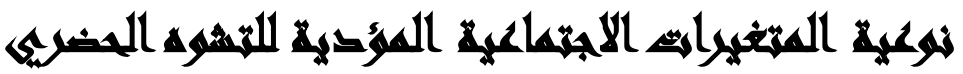

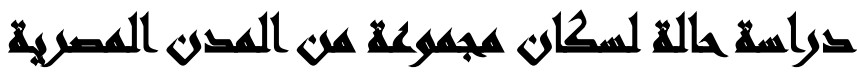

\section{[0]}

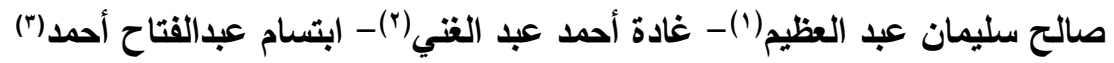

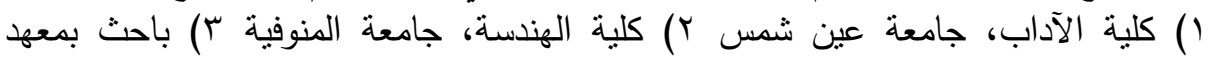
الدراسات والبحوث البيئية

\section{المستخلس}

هدفت الدراسة إلى التعرف على المتغبرات الإجتماعية المؤدية النتوه الحضري وطبقت

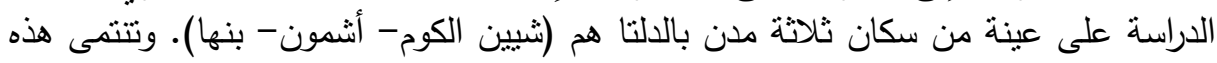

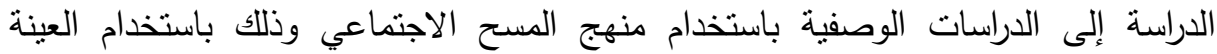

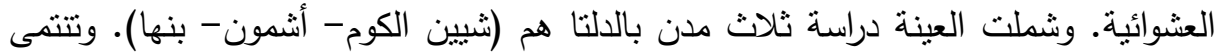

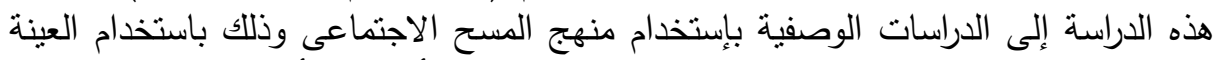

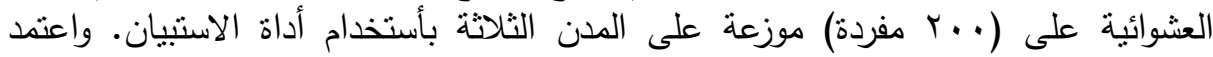

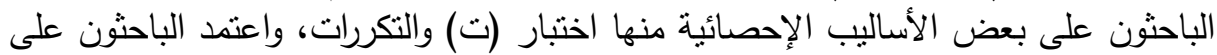
بعض الأساليب الإحصائية منها اختبار (ت) والتكرارات والنسب ومعاملاتلات الإن الارتباط.

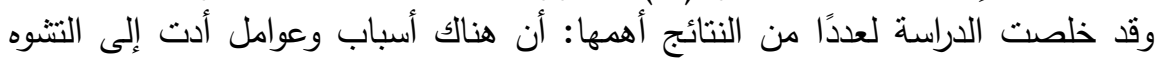

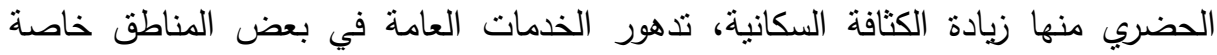

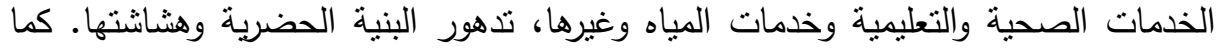

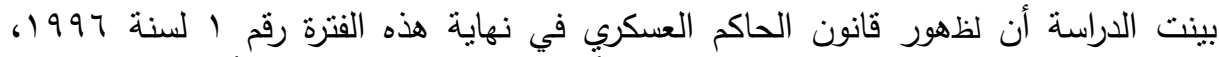

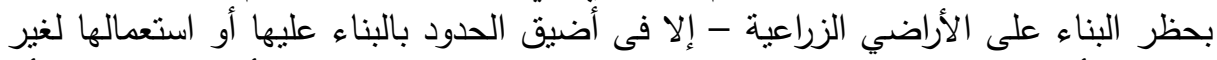

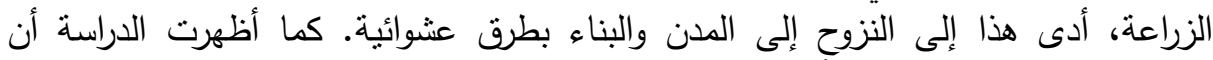

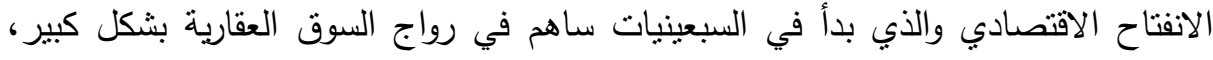

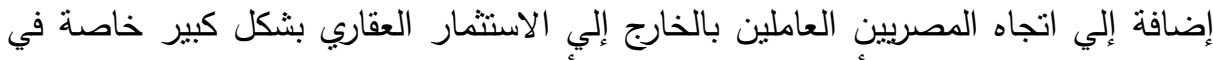

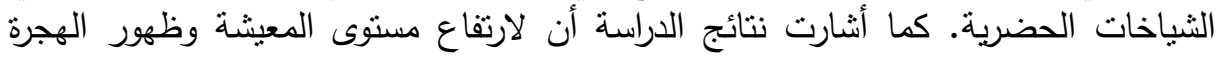

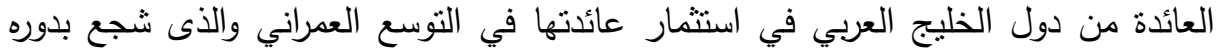

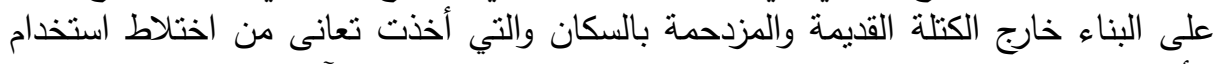

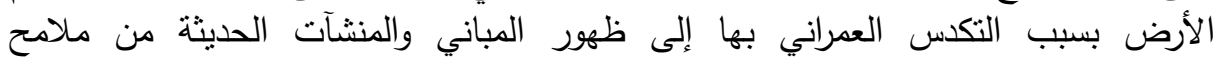

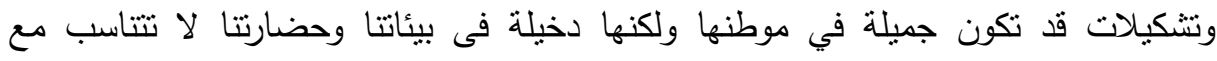

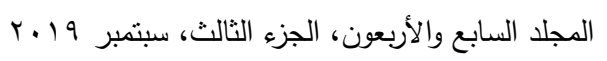




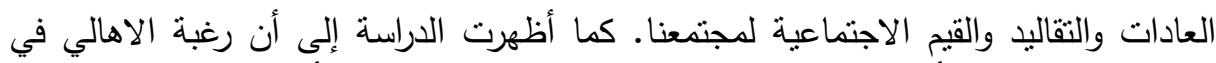

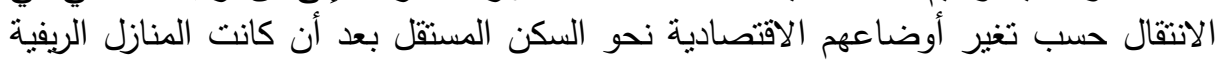

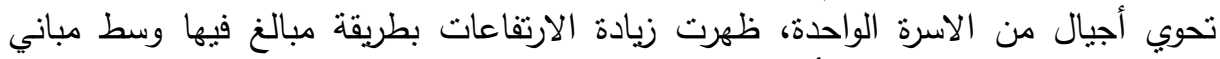

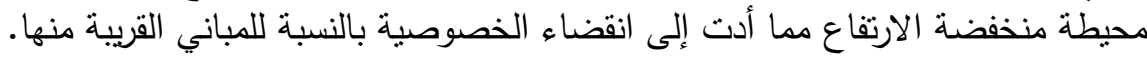

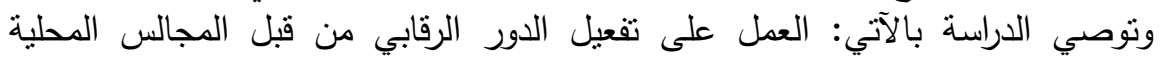

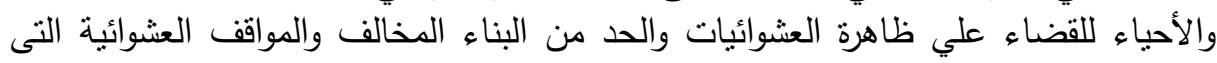
تعمل على تشويه المنظر الجمالي للمدينة. وضع اطرة التر تصميمية محددة لجميع المبانى داخل

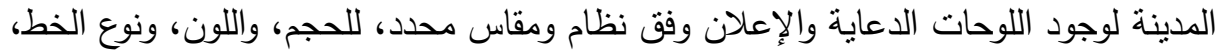

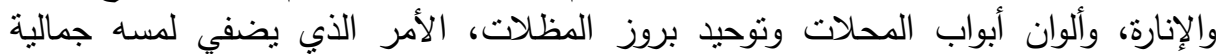

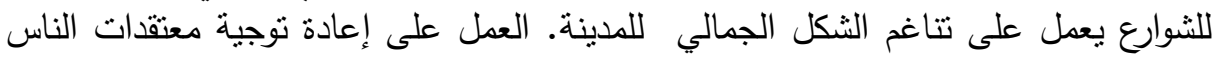

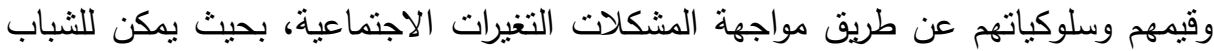

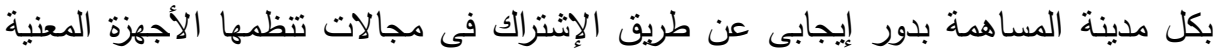

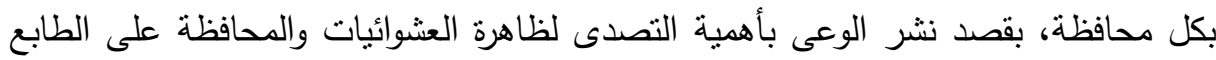
الحضاري للمدينة.

\section{Axis}

ظهرت مشكلة التشوه الحضري كظاهرة اجتماعية تجمع بين الظروف المادية والاجتماعية والاتجاهات الفكرية والقيم والمثل والعادات وأساليب الممارسة. وكأي ظاهرة فهي

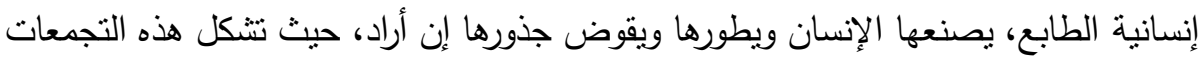

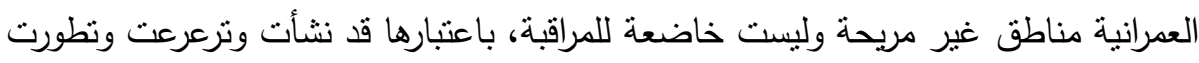

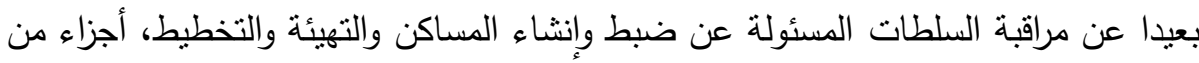
المدينة مزدحم بالسكان الفقراء، وانخفاض مستوى النمط العمراني ونوعية المساكن، وتسودها

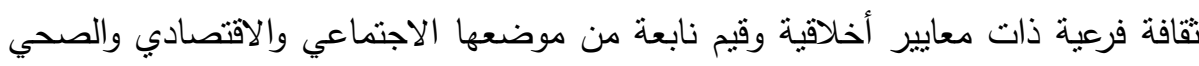

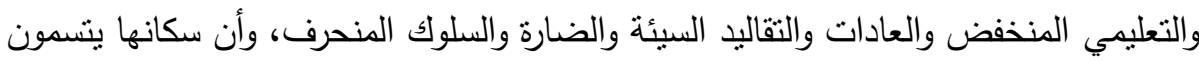

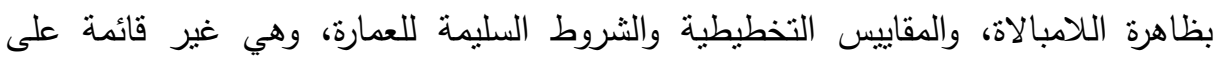

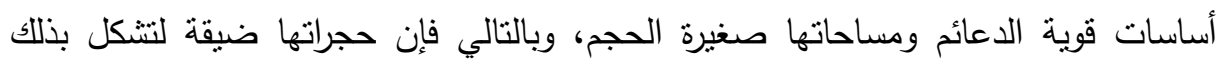

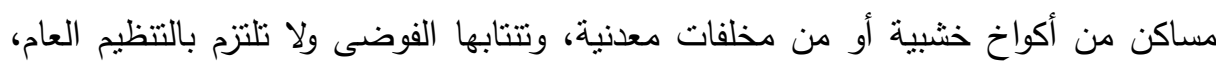

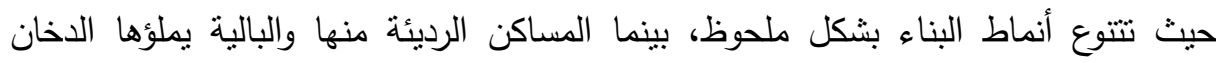


وروائح كريهة لاستخدام سكانها الخشب كوسيلة للوقود، أما تصميم هذه المساكن فيوحي بالفقر

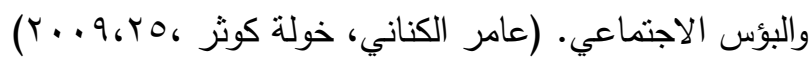

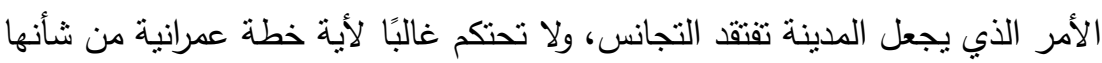

إعطاء المدينة الوجه اللائق بها، وهذا بسبب عدم القدرة على التحكم في الدينامية الطبيعية

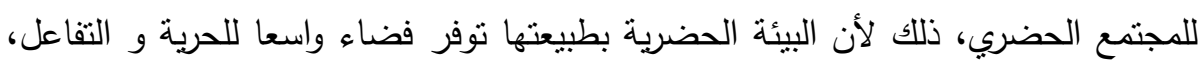
وتتميز بالتباين الثديد والمجهولية والميل نحو الفردية والنفعية في العلاقات الاجتماعية. (محمد لوندية

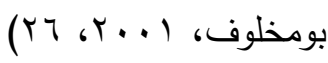

وقد أدى تعقيد الحياة الحضرية الحديثة، إلى خلق العديد من المشاكل الاجنماعية والبيئية الناتجة عن تفاعلات وتغيرات في السلوك الإنساني وتعامل أفراد المجتمع مع بيئاتهم، مما ساعد على انتشار التشوه الحضري خاصة مع أساليب التقدم الصناعي، والتتسع العمراني العشوائي، والتكدس السكاني، وقلة الوعى الاجتماعي والثقافي والبيئي ذلك على التشوه الحضري للمدن.

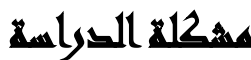

تأثرت المدن المصرية بالأوضاع السياسية والاقتصادية والاجتماعية التى تمر بها

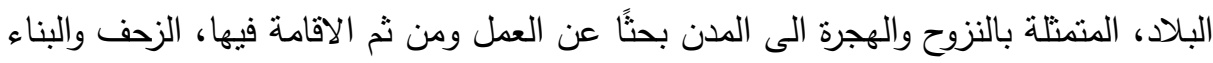

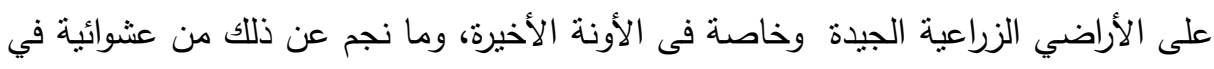

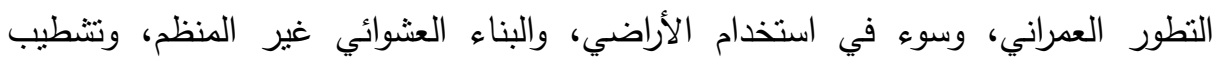
المباني وفق ذوق فردي، مما ينتج عنه ما يمكن تسميته التتوه الحضرى و البصري، وهذاء

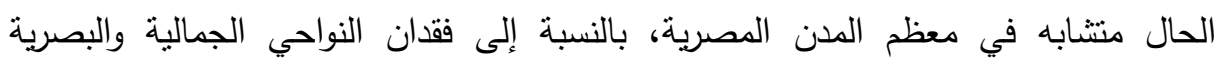
والتشوهات المعمارية في مداخل المدينة وشوارعها ووسطها التجاري. ويعود هذا التشوه الحضرى في مدن الدلتا إلى أسباب عديدة منها القوانين والأنظمة غير المتطورة، وغياب أنظمة التخطيط والتتظيم التي تحد من العشوائية، وسوء التصرف، وغياب التوزيع والتوازن 
الخدي، وعناصر الجذب البصري والتجاري، وتردي المستوى الثقافي وغياب الوعي

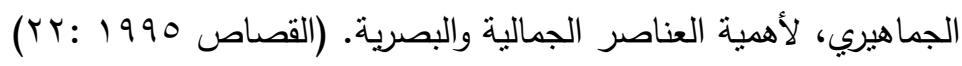

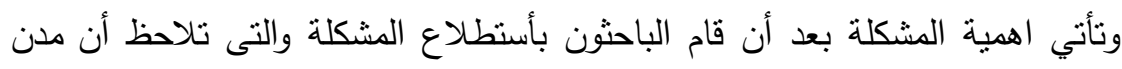
الدلتا تعاني من غياب التخطيط وخاصة فيما يتعلق بموضوع العناصر الجمالية والبصرية، حيث يسود المدينة التشوه البصري الناجم عن عشوائية البناء وعدم مراعاة الجوانب الجمالية والبصرية وعدم تطبيق الأنظمة والقوانين والتشريعات ذات العلاقة، ومن الدراسات التي تم الأستعانة بها دراسة كل من: ابراهيم مصطفى الدميرى بعنوان "الاعتبارات الجمالية والتلوث

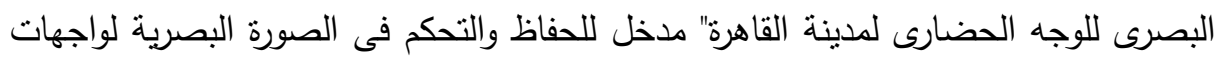

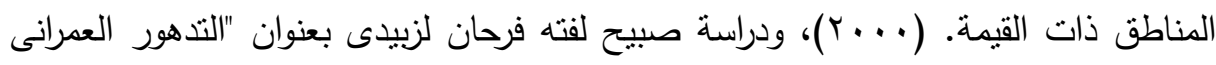

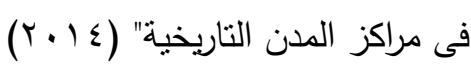
ومن ثم فان التشوه الحضرى هو نتاج التفاعل الإنسانى مع البيئة بمحتوياتها ومظاهر

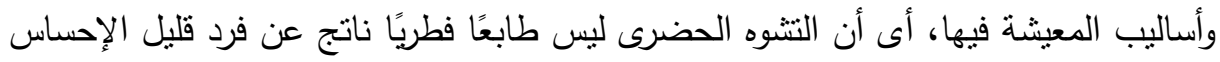
بالجمال وإنما هو طابع مكتسب نتيجة الإحتكالك بالبيئة الطبيعية الإنسانية المحيطة، باعتبارها ظاهرة اجتماعية بيئية يتسبب الفرد فى انتشارها، مما يجعل محاور ومركزية المدينة بجميع أحيائها مهددة بالخطر وهذا يؤدى إلى عرقلى باعلة مسارات التقدم والتطور واندثار الصورة الأصلية والحقيقية للمدينة.

وتأتي هذه الدراسة لتعالج هذه القضية الهامة والتي تتعلق بتحليل العوامل المؤدية إلى التشوه الحضرى في المدن ووضع بعض الحلول والمقترحات بهدف تحسين الصورة الجمالية

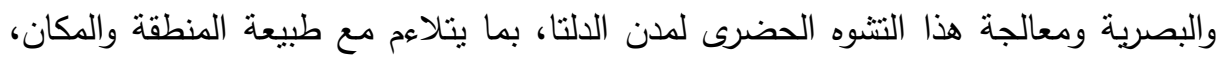

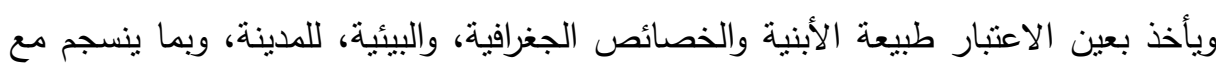
الثقافة العامة للمجتمع المصرى وبما يساهم في تسويق المدينة اقتصادياً وجمالياً.

\section{أهساهنغ التواسما}

1- تحليل العوامل المؤدية للتشوه الحضرى فى المدن المصرية. r- التعرف على المتغيرات الاجتماعية التى أدت إلى التشوه الحضرى التئ.

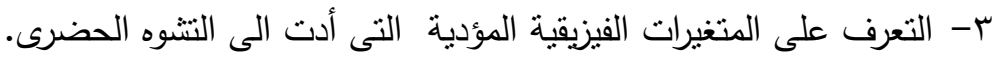

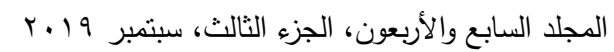


ع- التعرف على التغيرات التى طرأت على الأوضاع العمرانية فى مدن ومناطق الدراسة، وأسباب هذه التغيرات.

ه- وضع بعض الحلول والمقترحات التى تناهم فى تحسين الصورة الجمالية للمجتمع الحضرى.

$$
\text { كما نسعى هذه الدراسة إلى تحقيق مجموعة من الأهداف وهي: }
$$

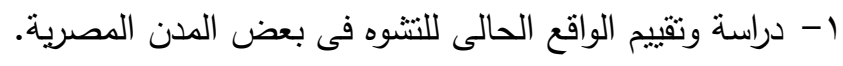
r- تحديد الموارد والإمكانيات التي تميز هذه المدن وخصائصها.

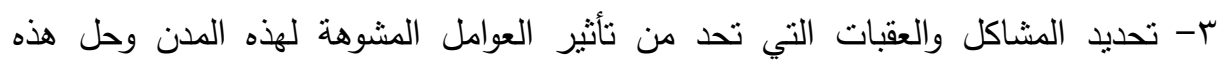
المشاكل.

$$
\text { ع- البحث في إمكانية تحقيق النطوير والتحسين في جميع الجوانب. }
$$

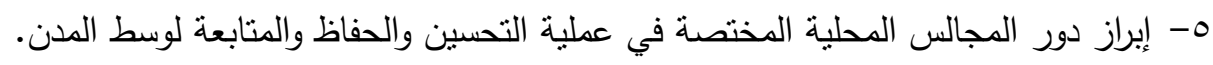
1- توضيح دور المجتمع ودور المشاركة الثعبية في الحفاظ واستدامة العناصر الجمالية لهذه المدن.

V- وضع استراتيجيات للمساهمة في المحافظة المتكاملة واستدامة الناحية الجمالية في المدن المستهدفة من الدراسة.

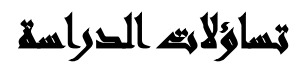

1- ما المتغيرات الاجتماعية المؤدية للتشوه الحضرى؟

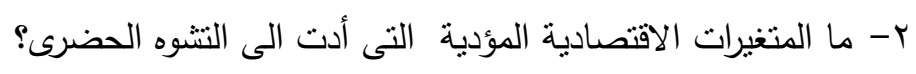

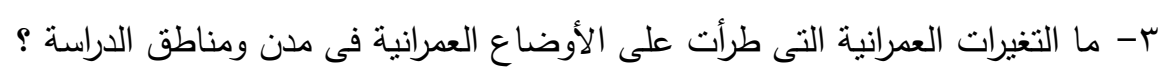
ع - ما مدى وجود إرتباط بين التثوه الحضري والمتغيرات الاجتماعية المرتبطة به ؟ 


\section{أهمي التوراسة}

تستمد الدراسة أهميتها من خلال:

- الحاجة الملحة لمعالجة التشوه الحالي التي تعاني منه المدن المصرية بشكل عام نظرا

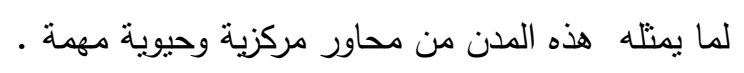

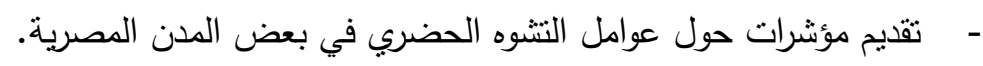

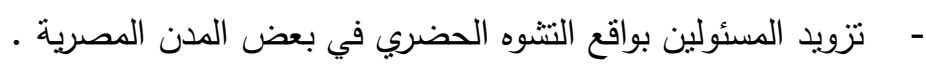

- - تعتبر الدراسة مهمة لمخططي المدن بوجه عام، ومخططي مدن الدراسة بوجه خاص.

الأهمية النظريةة: تتطلق أهمية الدراسة من قضايا نظرية تم إختبارها على الواقع

• التعرف على مدى وجود النتوه الحضرى فى بعض المدن المصرية.

تساهم فى معرفة أهم المتغيرات الاجتماعية والفيزيقية للتشوه الحضرى التشي.

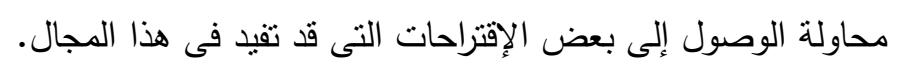

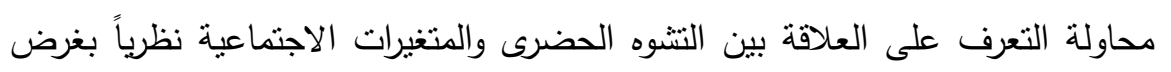

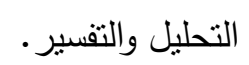

الأهمية المجتمعية: تتبع الأهمية المجتمعية للاراسة من كونها تهنم بدراسة التشوه الحضري

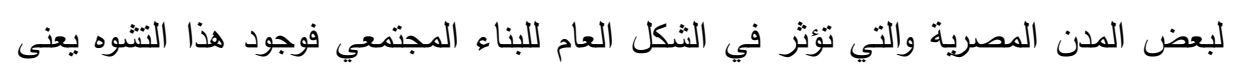

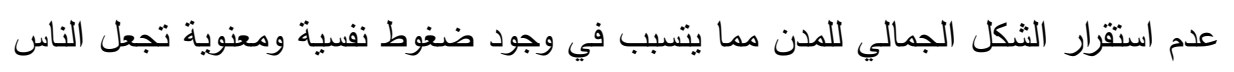

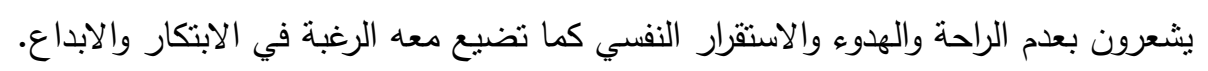

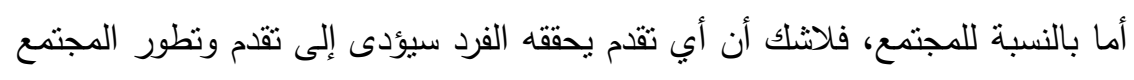

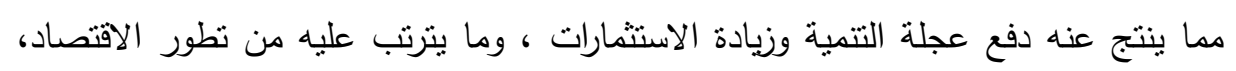

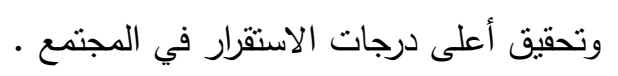

وبالتالي فإن لهذه الدراسة أهمية خاصة تتعلق بالتوصل إلى إلى هذه المتغيرات التهات الاجتماعية

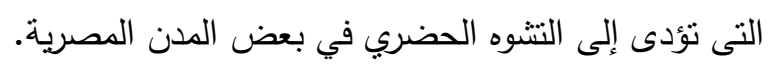




\section{مخاهيهر الترواسة}

مفهوم التشوه الحضري: النشوه الحضري يعرف بأنه تثويه لأي منظر نقع عليه عين

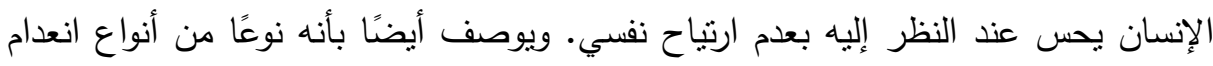

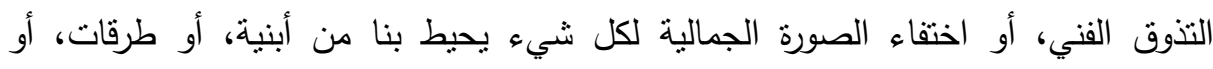

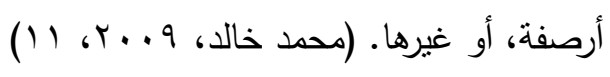

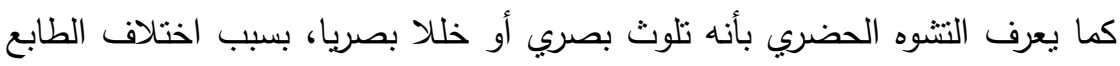

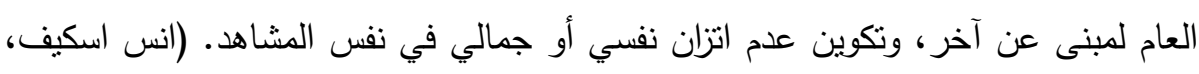

فالتعايش البصرى لانسان عادة ما يلعب دورا خطيرا في توجيه سلوكياته ، وتتعكس

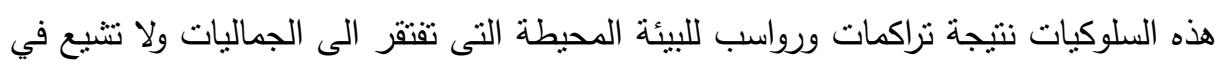

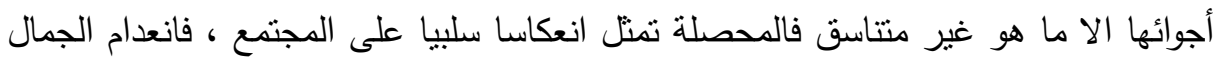

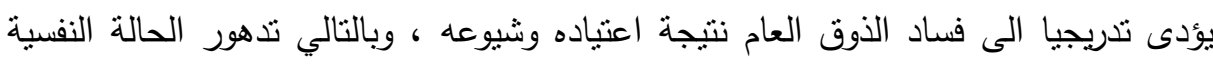

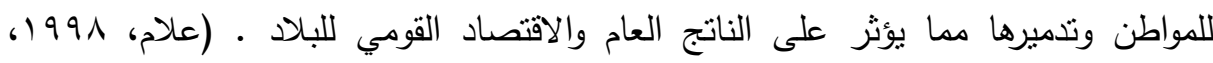

\section{تعريف المتغيرات الاجتماعية: وتم تتاولها بالتوضيح كالآتي:}

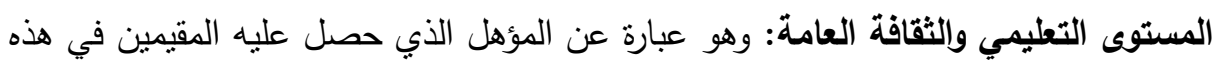

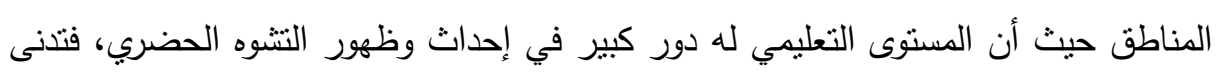

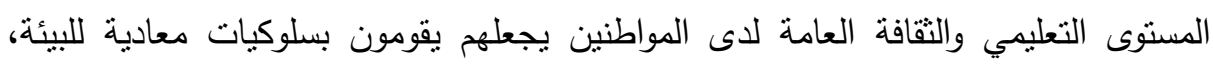
وذلك من خلال تصرفاتهم وعدم الاهتمام ببيئة المدينة. الثقافة الاجتماعية: وهى الثقافة التى يحملها الساكن من البيئة القادم منها إلى الدينة، حيثة حيث

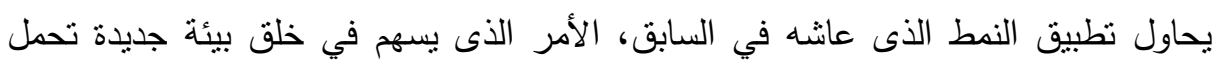

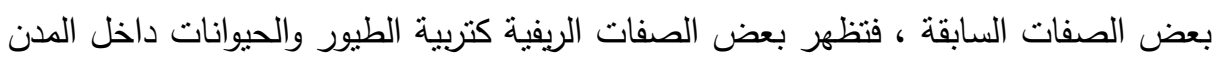

$$
\text { الذى يعمل بدوره على نتشويه المدينة. }
$$


ضغوط الحياة: وتقصد به الباحثة مدى تعرض كل فرد من الضغوط والأعباء وكم المصاعب

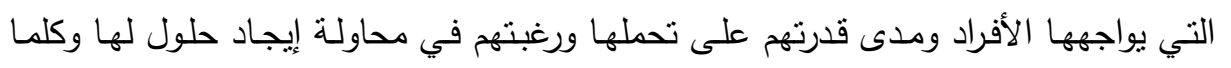

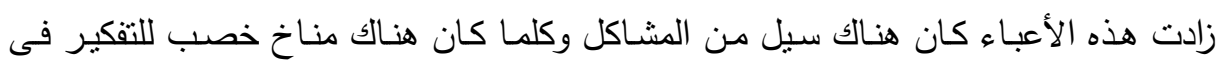

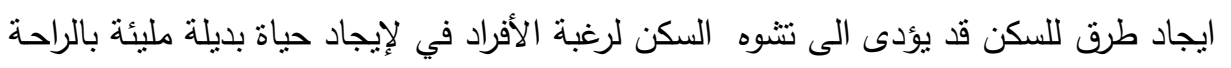

$$
\text { والرفاهية. }
$$

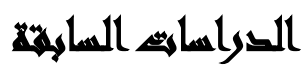

$$
\text { أولاً: الاراسات التى اهتمت بالجانب الاجتماعي: }
$$

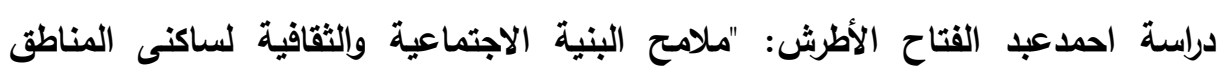

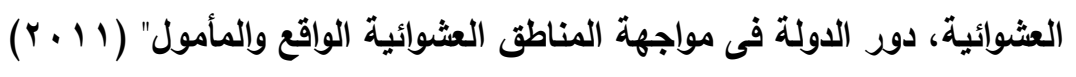

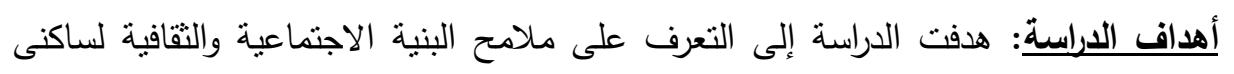
المناطق العشوائية دور الدولة فى مواجهة المناطق العشوائية "الواقع والمأمول".

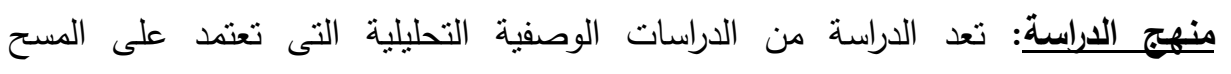

$$
\text { الإجنماعى بالعينة. }
$$

المجال المكانى للاراسة: طبقت هذه الدراسة على منطقة (الثيخة شفا) احدى مدن بورسعيد. نتائج الدراسة: توصلت الدراسة إلى مجموعة من النتائج وهى أن مشكلة المناطق العشوائية

$$
\text { من المشكلات المركبة، والتى ترجع إلى مجموعة من الأسباب أهمها: }
$$

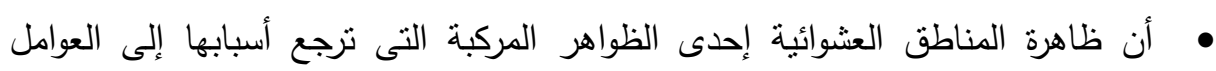

$$
\text { الإجتماعية والثقافية والإقتصادية والديمقراطية والسياسية. }
$$

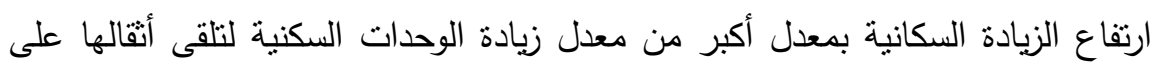

$$
\text { الدولة من جانب وعلى ساكنى المنطقة من جانب آخر . }
$$

تتوع المشكلات الأسرية المنتشرة فى المنطقة، انتشار وتتوع الأمراض فنى في منطقة

$$
\text { الدراسة. }
$$

-العمل على تحقيق الموائمة الكاملة بين السياسات الاقتصادية والاجتماعية ومنطلبات 


\section{ثانياً: الاراسات التى اهتمت بالتشوه العمرانى:}

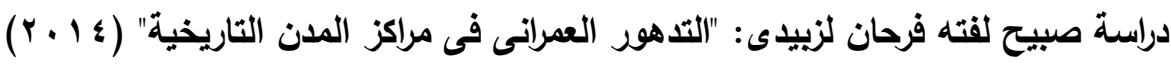
هدفت الدراسة الى بناء قاعدة معرفية لظاهرة التدهور العمرانى للبيئة السكنية فى مراكز

المدن التاريخية. نتائج الدراسية: كانت من النتائج التى توصل اليها البحث تدهور البيئة العمرانية للمساكن فى من من منطقة الدراسة لمعاناتها من الرطوبة وقلة تعرضها للثمس وضيق مساحة المسكن، مما أثز على النواحى الصحية للسكان، حيث يؤثز وجود الرطوبة ونساقط البياض وضيق مسته مساحة

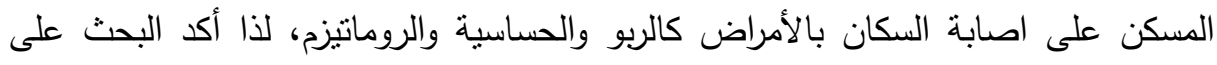

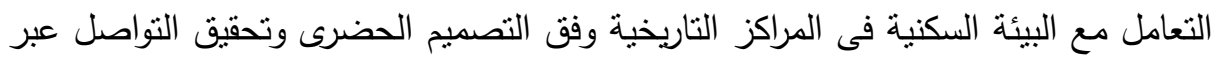

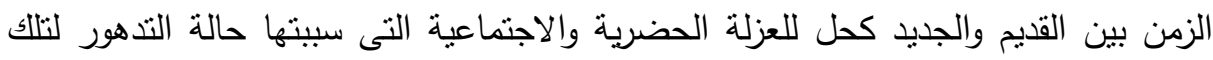

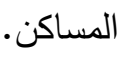

دراسة ايمان جلال أحمد جلال "النمو العشوائى للمدينة" ( ب 99 1 ) أهداف الاراسة: هدفت الدراسة إلى التعرف على ملامح النمو العشوائى فى مدينة القاهرة، والخصائص الأبكولوجية والإجتماعية والإقتصادية للمناطق العشوائية. المجال المكانى والبشرى: اختيرت منطقة عزبة الهجانة لفهم التجمع البشرى، كيف نشأ وكيف ولفئ تطور وفى أى ظروف. منهج الدراسة: تعتبر الدراسة من الدراسات الوصفية التحليلية وقد اعتمدت على المسح

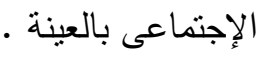
نتائج الدراسة: نوصلت الدراسة إلى النتائج الآتية: ارتفاع نسبة المهاجرين إلى محافظة القاهرة. • تلعب الهجرة الريفية الحضرية دور هام فى نمو المدن حيث اوضحت غالبية البهن العينة أنها من مواليد غير القاهرة. 


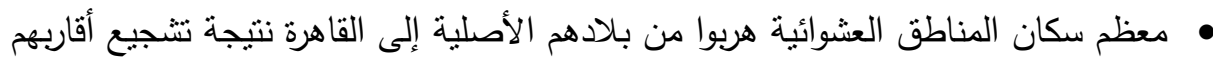

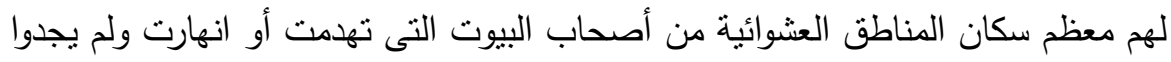
مأوى لهج.

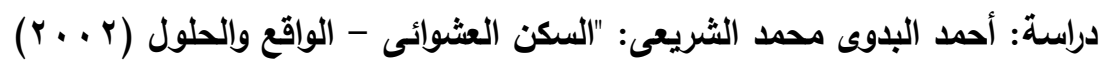

أهداف الدراسية:

- - هدفت الدراسة إلى إخضاع ظاهرة العشوائيات التى تعانى منها معظم المدن المصرية

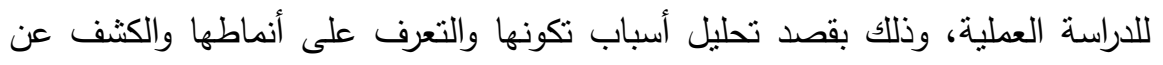
أساليب الحياة بها وذلك من خلال التعرف على خصائص سكانها وأوضاع السكن بها وطرح أهم البدائل لمواجنتها وذلك فى ضوء ودئ رؤية جغرافية حقيقية للظاهرة.

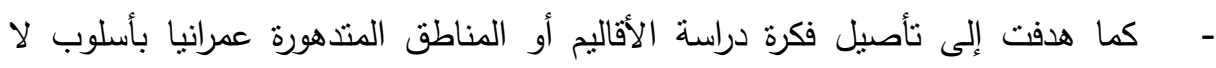
يعتمد على وصف الظاهرة بقدر ما تعتمد على اكتثاف وتحديد خصائص هذه الظاهرة من خلال الدراسة الميدانية. - - كذلك تأكيد بعض المفاهيم الهامة ومنها تتشديد المراقبة على المناطق الثناغرة حتى يتم تلافى نشوء مناطق عشوائية جديدة مما يعوق النمو الطبيعى للمدن.

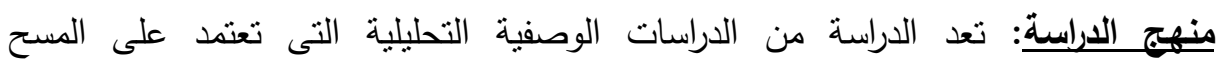
الإجتماعى بالعينة. نتائج الدراسة: نوصلت الدراسة إلى أنه يجب تعديل بعض السينة السياسات والتشريعات التى تأخذ

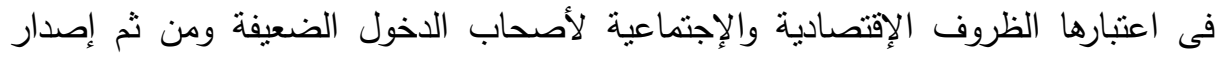
قوانين ولوائح ومعايير تخطيطية وتتظيمية تتلائم وامكانية هؤلاء فى حصولهم على سكن ملائم. 


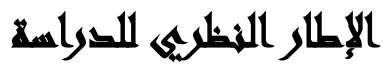

التثوه الحضري في مصر : تحليل تاريخي اجتماعي: أولاً: محدات التشوه الحضري: ولقد أدت مشكلة الإنكان وامتداد العمران أفقيًا ورأسيًا بصورة

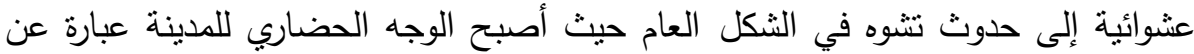

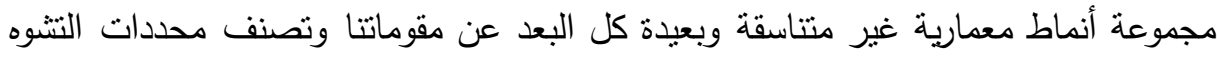
الحضري التى بمكن ملاحظتها ومشاهدتها في الددن المصرية كالآتي: (طارق جمال الدين، $(r \cdot 61990$

التثبوه الحضري الساكن: عبارة عن مجموعة العناصر الثابتة الموجودة في الددينة، والتي يكون

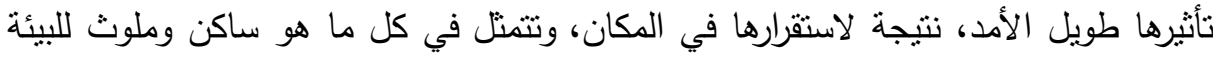

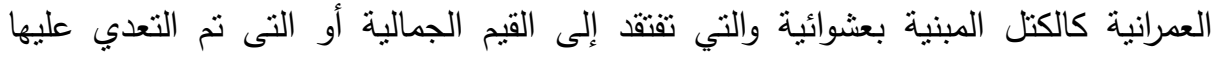

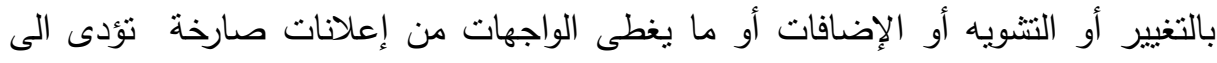
تنثوه المظهر المعماري والجمالي.

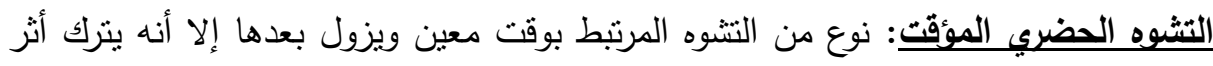

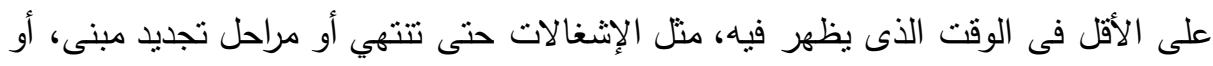

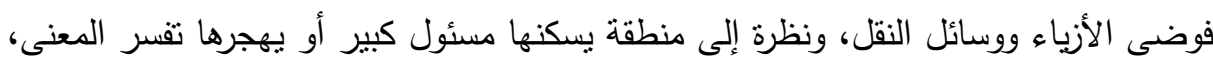

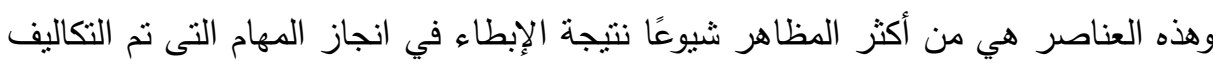
بها، أو التهاون في تتفيذ هذه المهام. التثثوه الحضري المستورد: ينمثل في الأثكال التى وفدت إلينا من بيئات أخرى أو تم تطبيقها

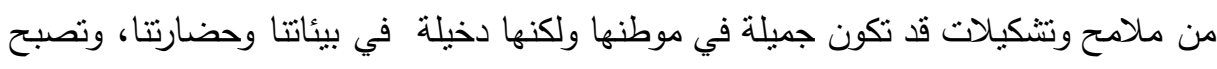

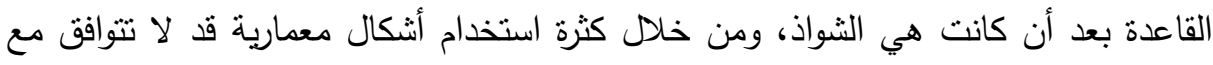
المجتمع أو البيئة الموضوعة فيها. 
التشوه الحضري المتعايش: وهو التشوه الذى تتم مقاومته في البداية ثم لا نستطيع تغيره

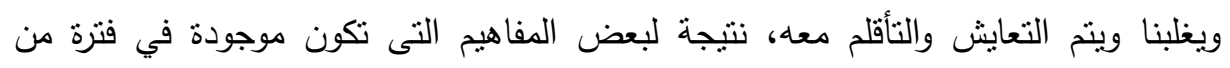
الفترات، كالإكثار من استخدام الزجاج أحيانا والزخارف أحيانا أخرى. ثانياً: أبعاد وأثنكال التشوه الحضري: بعتبر تحقيق الجمال مطلبًا أساسيًا لأى تكوين معماري التهاي فى أى مجتمع و في أي عصر من العصور، فالإحساس بالجمال مطلوب في العئرة المباني والإنثاءات بأثنكالها المختلفة.

وإذا قل أو اختفى الجمال وحل محله المناظر القبيحة والمشوهة بعتبر هذا تشوه

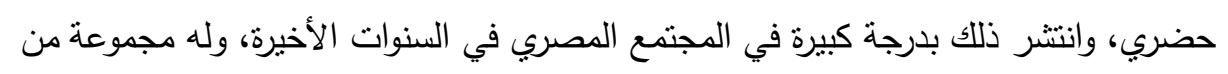

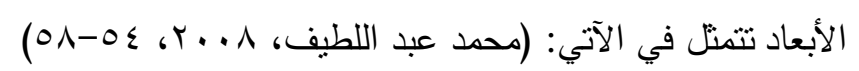

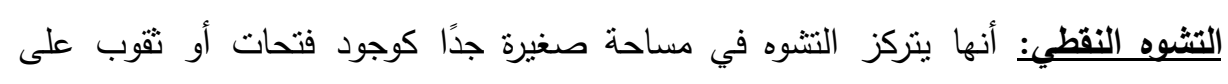
واجهات المباني الناتج من عمليات البناء أو آثار بعض النهاء لأسلحة على المباني التى حصلت

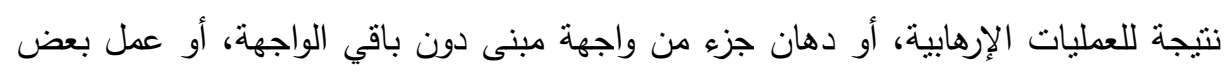
القطع الزخرفية على واجهات المباني. التشوه الخطى: فالتشوه الخطى أكثر ملاحظة لأنه ينفذ في حيز أكبر فتتمثل في أعمدة الإنارة وعدم انتظام لأسلاك الكهرباء والهاتف فوق المباني وعدم تتسيق ألوانها وأثنكالها.

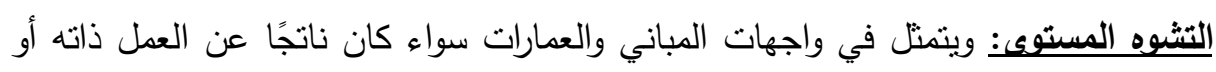

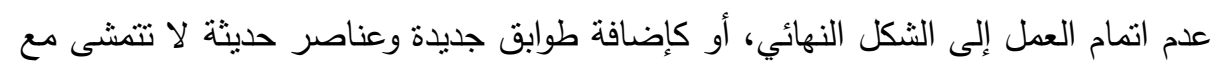

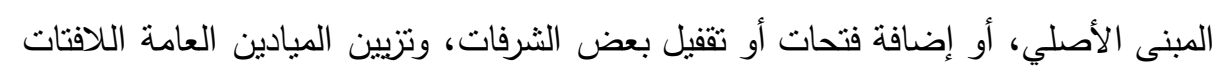
والاعلانات.

التشوه الكتلي: هو الذى يفقد فيه المبنى جوهره ونظامه وتصبح عناصره غير مرنبة، فيصبح

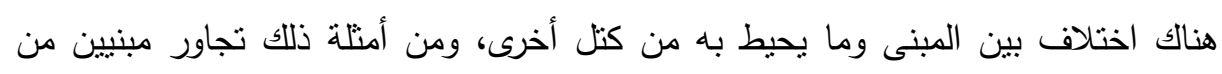

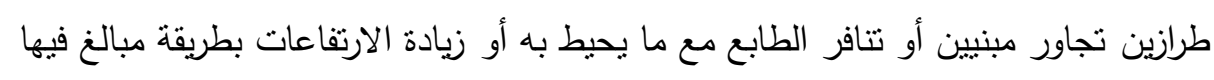

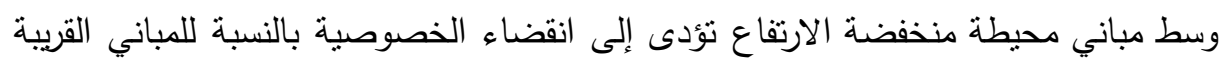


التشوه اللوني: هو الذي يحدث نتيجة فوضى تعدد الألوان في المبنى بطريقة غير متتاسقة مع

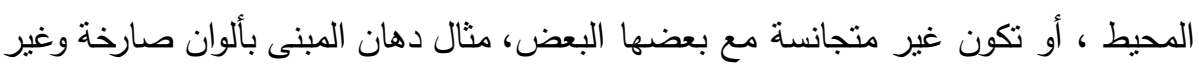

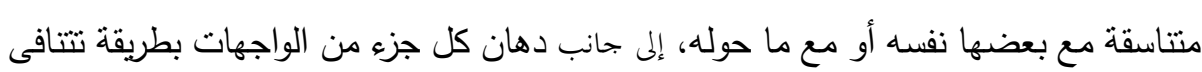

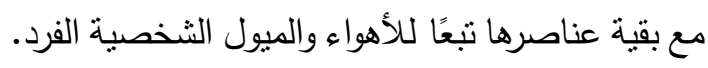

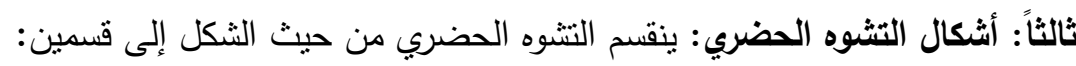

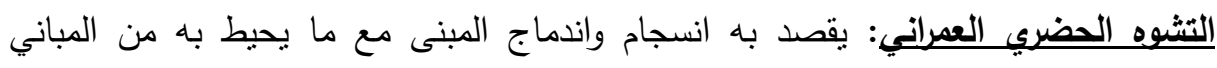
القريبة منه والفرغات التي تخلق جميعها مناطق ذات قيمية وظيفية وجمالية، وتكون هذه

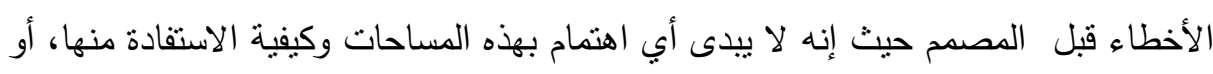

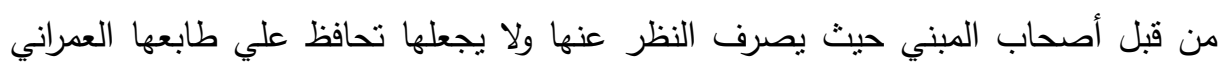

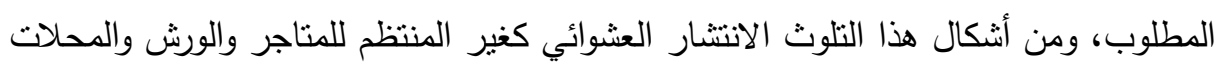

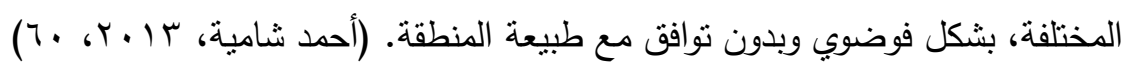
التشوه الحضري المعماري: وهو أي تغير في الصفة الأصلية للمبنى، وينتج هذا لعدة أمور

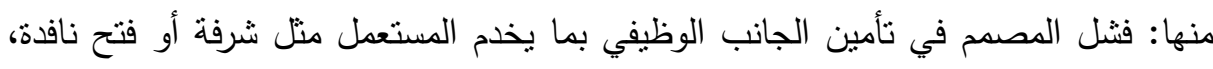

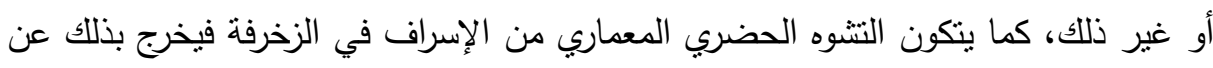

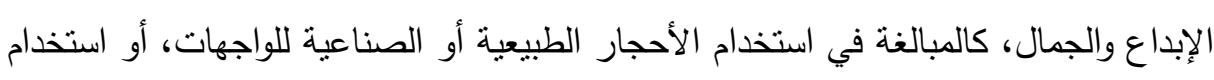

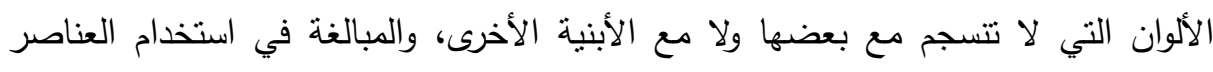

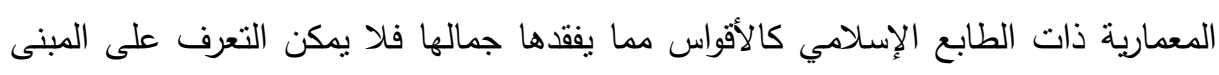

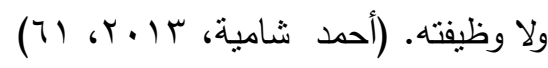
رابعاً: العوامل والظواهر المؤدية إلى التشوه الحضرى فى المدن المصرية: التشوه الحضري

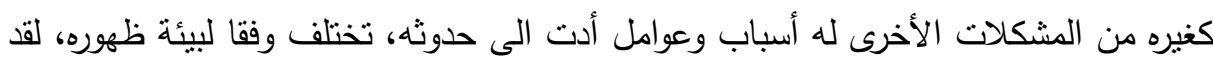

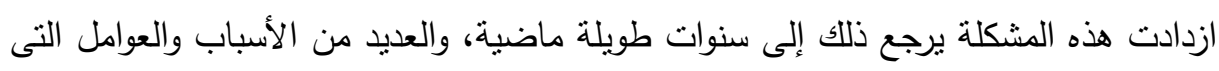

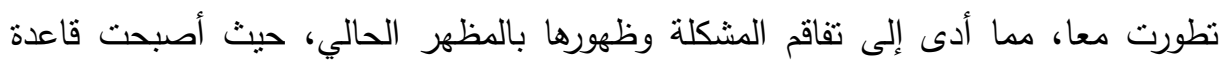
أساسية في كثير من المباني والمدن المختلفة، يمكن تحليل الأسباب والعوامل المؤدية للتشوه 
الحضري في المرحلة المعاصرة، باعنباره أمرًا ضروريا حتى يسهل عملية الحد من التشوه

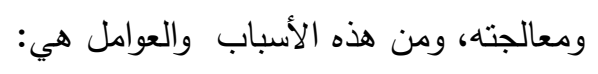

أولاً: العوامل الاجتماعية: ومنية

الجولب السلوكبة في المجتمع المصري: لا يعتبر التشوه الحضري رؤية فنية أو حضارية

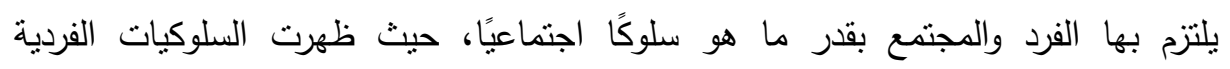

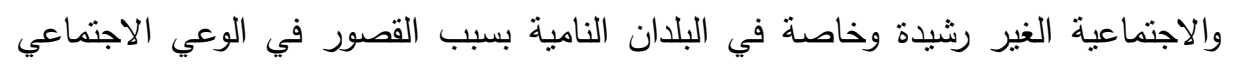

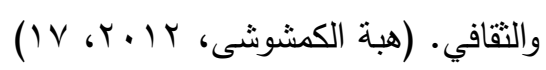

أثر الازلحام والكثافة في مصر على البيئة السلوكية: هناك تأثثر كبير في الجوانب السلوكية الفردية والاجتماعية التى تتركها الحياة من مكان دون آخر، ويختلف هذا التأثير باختلاف التائه

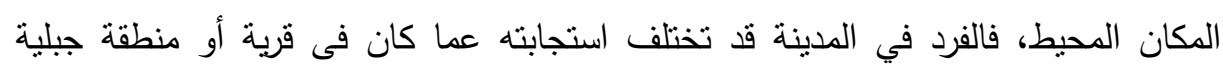

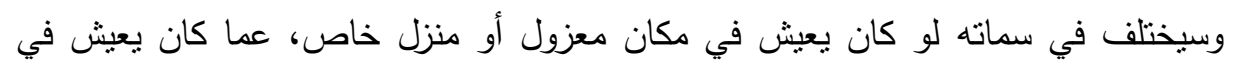

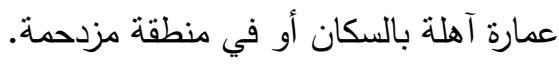

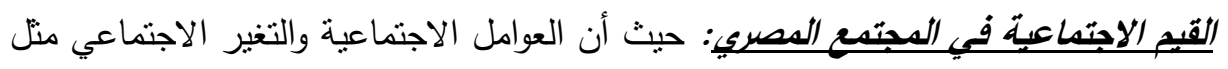

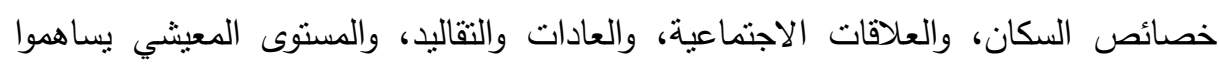
بشكل كبير في حدوث التشوه الحضري.

لذا تعتبر القيم الاجتماعية محددًا لسلوك الفرد وأفعاله فكثير من الأنماط السلوكية التى في

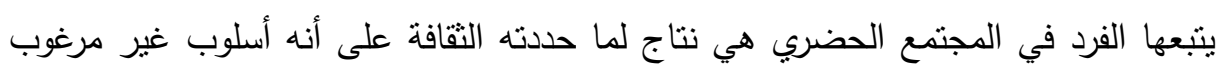

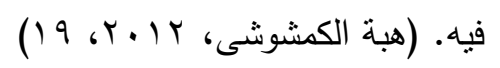
وتعرف القيم على أنها المعتقدات التى يحملها الفرد نحو الأشياء والمعاني وأوجه النشاط المختلفة ( دراسة بحثية ، ^ . . Y)، فتحدد له أهدافه العامة في الحياة والتي تتضح من خلاهل

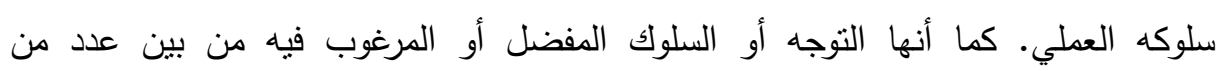

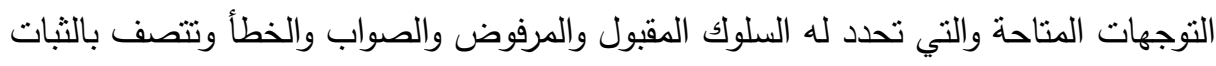

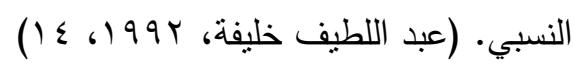


الثقافة العامة للفرد: لقد ظهرت السلوكيات الفردية الغير رشيدة وخاصة في البلدان النامية بسبب القصور فى الوعى الاجتماعي والتقافي، فالحديث عن البيئة ومحتوياتها ومؤنراتها يقودنا

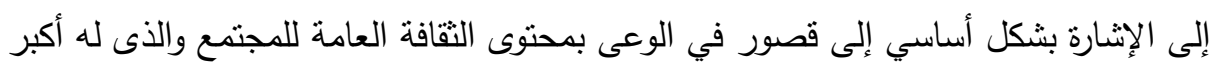

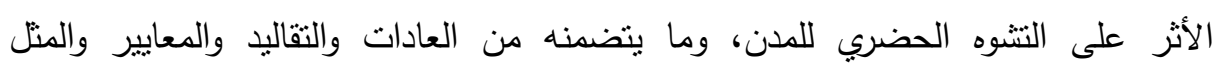

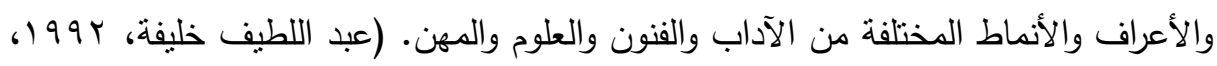

نظريات الدراسة : الجودة الإجتماعية - الضغط البيئى - البنائية الوظيفية.

\section{الإجبراءاهت المنهبجية}

نـوع الدراسـة: Type of study يندرج نوع الدراسـة الحالية تحت إطسار الدراسـات

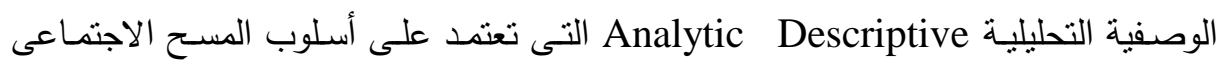

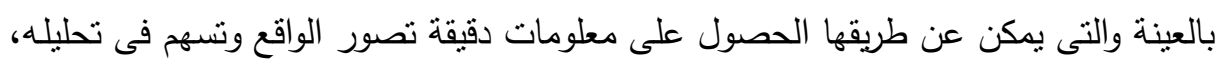

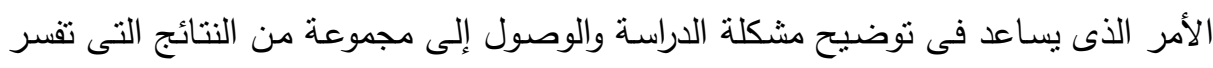
موضوع الدراسة.

ومن هنا فقد كانت هذه الدراسة ضمن إطار الدراسات الوصفية التى تهدف إلى محاولة التعرف على أبعاد التشوه الحضري، وطرق مواجهنها ومحاولة ايجاد حلول لها.

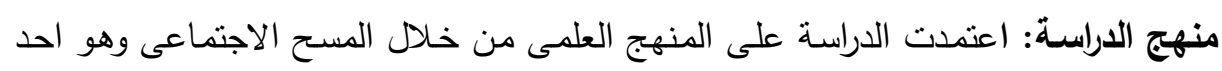

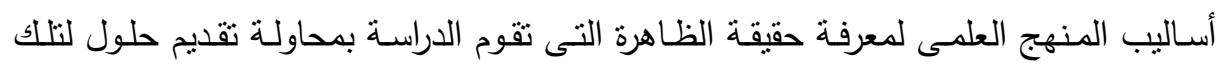
الظاهرة. ومن هنا نرى الأسلوب المنهجى الذى ينتاسب وطبيعة الدراسة تمنل فى الأسلوب الوصفى التحليلىDescriptive Method بأستخدام أسلوب المسح الاجتماعى بالعينة، ويتسم منهج المسح الاجتماعى بالعينة sample social survey والذى يعد من اكثر المناهج 
العلمية استخداماً وشيوعاً فى البحوث الاجتماعية للتطبيق على العينة، حيث يعتبر مرحلة أولى وهامة للبحث الإمبريقى.

مجالات الاراسـة: من الخطوات المنهجية الهامة فى تصميم البحوث هو تحديد مجالاتها

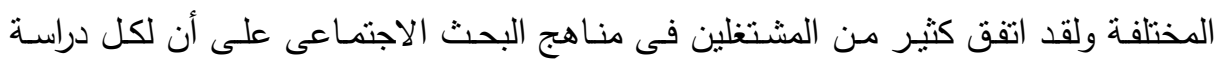
مجالات ثلاتـة رئيسية يجب على الباحث توضيحها عند تخطبط إجـراءات البحث وهذه فئه

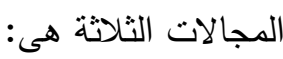
المجال المكاني للاراسة: ويقصد بالمجال الجغرافي هو النطاق المكاني لإجراء الدراسة وفى

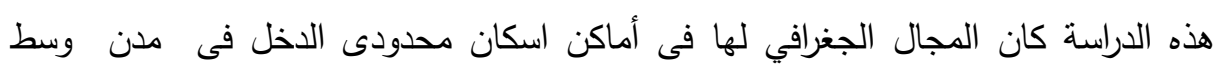

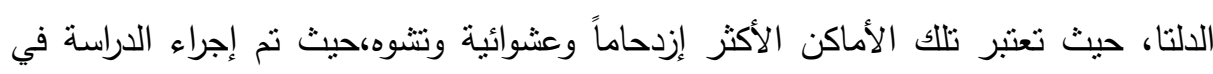
المدن المستهدفة وهى مدينة (بنها وأشمون وشبين الكوم). المجال البشري للاراسة: تقتصر الدراسة على سكان مدن الدلتا وقد تم اختيار مدن شبين

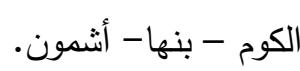
المجال الزمني للاراسة: استغرقت الدراسة الميدانية قرابة الثلاثة أنثهر، ابتداء من شهر يناير

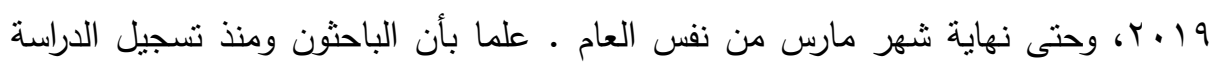

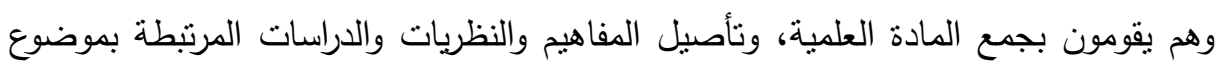

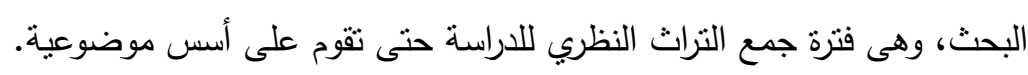

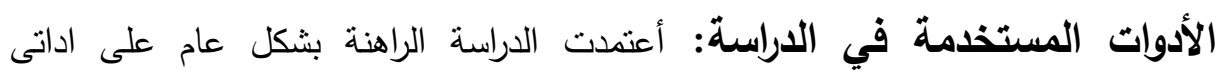
الإسنتيان (Questionnaire) ودليل دراسة الحالة لتحقيقهما هذا الهدف العام كإحدى أدوات جمع البيانات. صدق وثبات ادوات الاراسة: اعتمدت الباحثة في التحقق من صدق الاسنتيانات على صدق

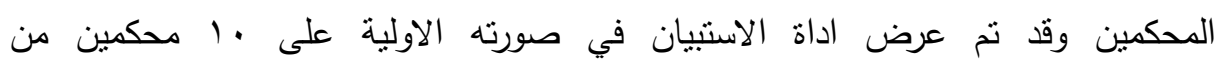
المتخصصين في علم الاجتماع البيئي وعلم الاجتماع والهندسة. وقد تم حساب الثبات لادوات الدراسة باستخدام طريقة اعادة الاختبار حيث فالئماع وام الباحثة

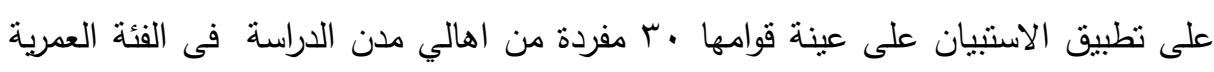
الأكثر من •. سنة والمسئوليين التنفيذيين بها. 
عينة الدراسة : شملت عينة الدراسة ( . . ب) مفردة من أهالى مدن الدراسة فى الفئة العمرية

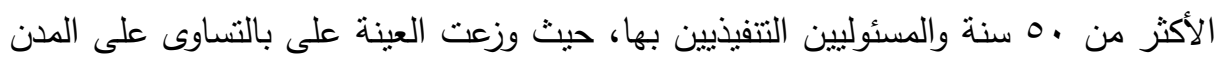
الثلاثة للاراسة ونم اختبار عينة عمدية وفقاً لمعادلة التمثيل الإحصائي. جدول (1): نمو سكان محافظة المنوفية ومدينة شبين الكوم في الفترة من 1977 حتى 1974 $r .17$

\begin{tabular}{|c|c|c|c|c|c|}
\hline \% من & معدل النمو & سكان شبين الكوم & معدل النمو & سكان المحافظة & التعداد \\
\hline$\varepsilon, 00$ & $\Gamma_{6} \leqslant 0$ & รтrя. & 1619 & $1 \leqslant 0 \wedge \cdot \leqslant \wedge$ & 1977 \\
\hline 76.1 & 0.01 & $1 . r \wedge .0$ & $16 V$ & $|V| \cdot \lambda \leqslant q$ & $19 \times 7$ \\
\hline 0,90 & r.人T & Irr. & r.9^ & סוTIO & 1917 \\
\hline 0.71 & 1.17 & $107 V 9 \leq$ & t.TE & $r V T . \leq M I$ & 1997 \\
\hline $0, \varepsilon r$ & $1, r$ & IVVIIT & r.l & $r r V \cdot \leq r)$ & $r \ldots T$ \\
\hline$\varepsilon, 00$ & r.o. & rTq7Y & r.T. & $\leq r \cdot 17.1$ & $r .17$ \\
\hline
\end{tabular}

المصدر: من عمل الباحثة بالاعتماد على التعدادات السكانية لمحافظة المنوفية ومدينة شبين الكوم،

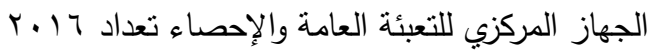
من خلال تحليل الجدول رقم (1) يتضح أنه تم تسجيل أعلى معدل نمو سكاني بمدينة

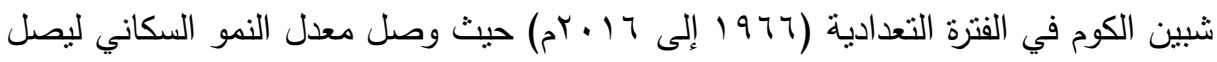
إلى أعلى معدلاته حيث بلغ (0101\%) سنويا، ويرجع الارتفاع الثديد في معلات النمو السكاني في الفترة السابقة إلى ضم كل من شياخات كفر المصيلحة وميت خاقان إلى الحدود الإدارية لمدينة شبين الكوم عام سو9 ام، وبضم تللك الثياختين للمدينة تعدى الحاجز السكاني لها المائة ألف. لإداله

ثم انخفضت معدلات النمو السكاني بعد ذلك في الفترات التعدادية السكانية الثلاثة

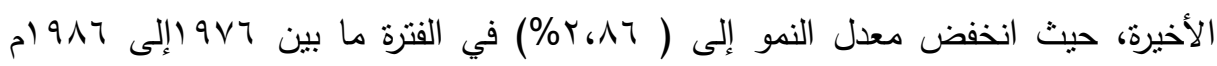

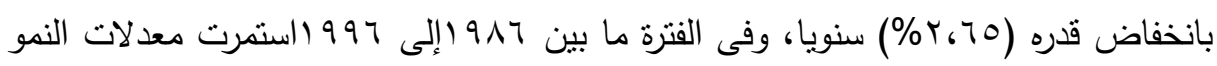
بالانخفاض حتى بلغت (†^، (\%) سنويا بانخفاض قدره (1\%) عن الفترة التى سبقتها، 


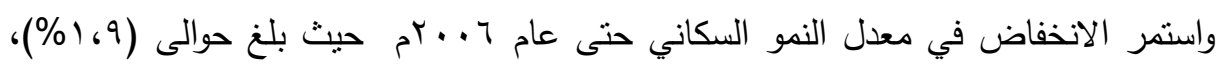

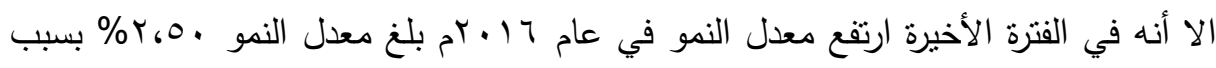

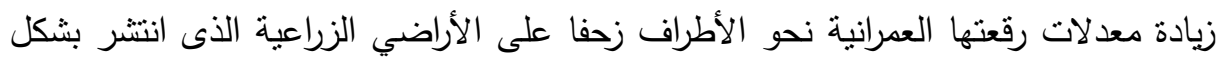

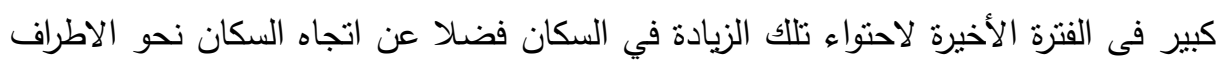

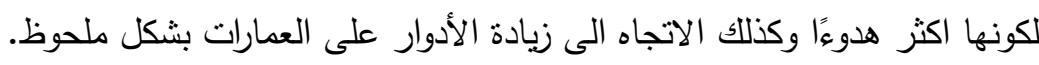

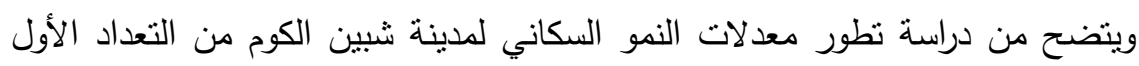
حتى التعداد الثالث عشر أن هناك أربع مراحل نتضح فئن في الآتي: المرحلة الأولى: انخفض معدل النمو السكاني واستمرت ست تعدادات على مدى العى

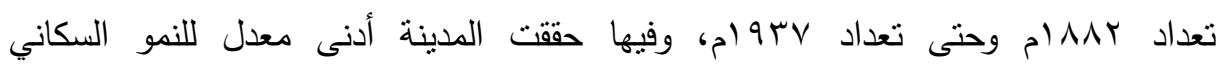

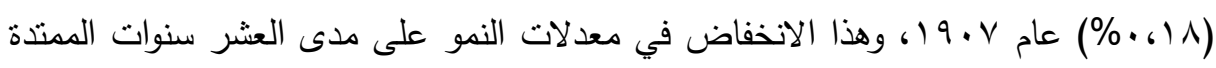

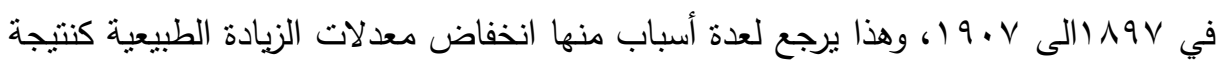
لارتفاع معدلات الوفيات، والتي زادت في بعض السنوات عن هب في الألف لانتشار الأوبئة والأمراض، بالإضافة إلى أن المدينة فى ذلك الوقت لم تكن أخذت وظيفتها الإدارية الكاملة.

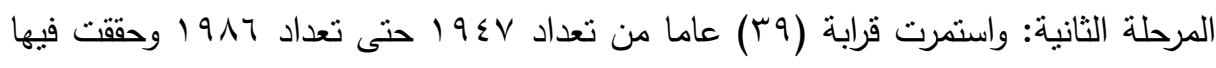

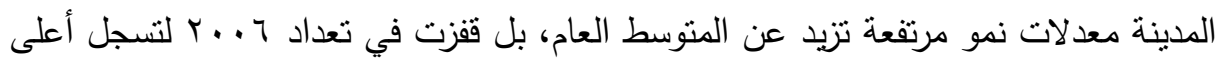

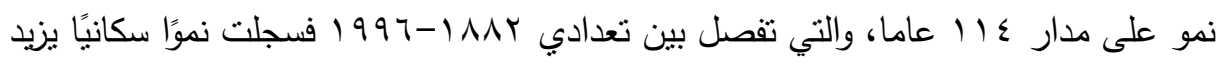
عن المتوسط العام بنحو (T، Y) مرة، ويرجع ذللك ضم قريتي كفر المصيلحة وميت خاقان

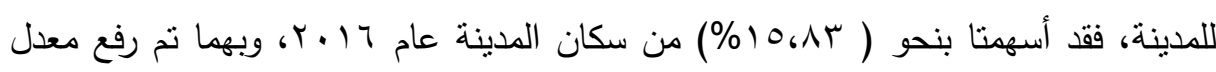

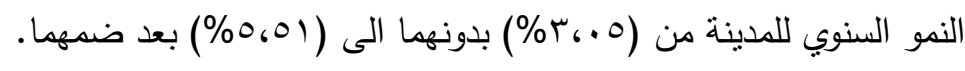

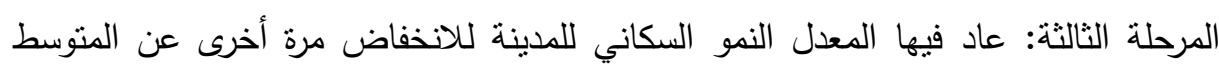
العام للنمو السكاني للمدينة لتسجل (7/, ا (\%) سنويا. المرحلة الرابعة: ارتفع المعدل النمو السكاني للمدينة عن المتوسط العام للنمو السكاني للمدينة

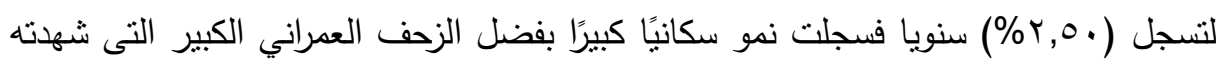
المدينة في الفترة الأخيرة. 
جدول (Y): تطور نسبة النمو السكاني بمدينة أنمون في الفترة من 1977 حتى 17 ـ 19

\begin{tabular}{|c|c|c|c|}
\hline معدل النمو السكاني\% & الزيادة الكلية & عدد السكان & الفترة \\
\hline حضر & النسبة المئوية & (نسمةة) & التعدادية \\
\hline$r_{6} T^{2}$ & Kr,A & r.0Tा & $19 \times 7$ \\
\hline$r_{6} V$ & $r v_{6} q$ & $\varepsilon r \cdot V q$ & 1917 \\
\hline$r_{6} 0$ & rY.r & OrITr & 1997 \\
\hline$\varepsilon_{6} 0$ & TrGs & ATqM & $r \ldots r$ \\
\hline$r_{6} \wedge$ & TrGT & V & $r .17$ \\
\hline
\end{tabular}

المصدر : من عمل الباحثة اعتمادًا على: الجهاز المركزي للتعبئة العامة والإحصاء، والثاء والنتائج

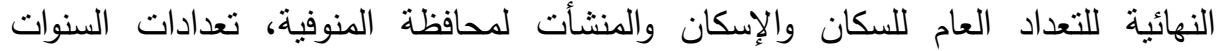

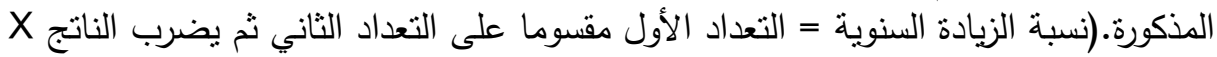

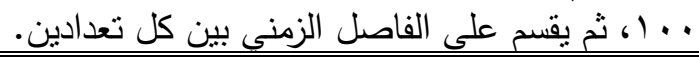

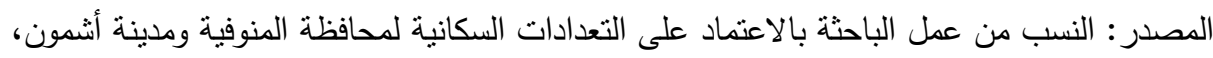
الجهاز المركزي للتعبئة العامة والإحصاء.

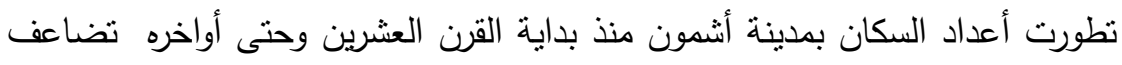

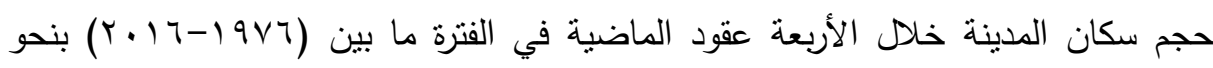

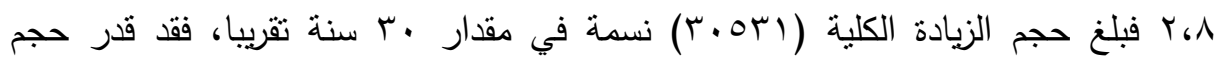

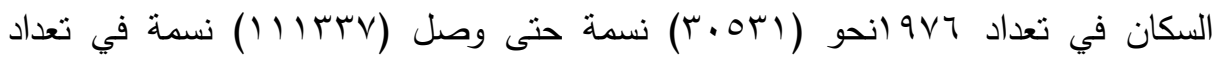

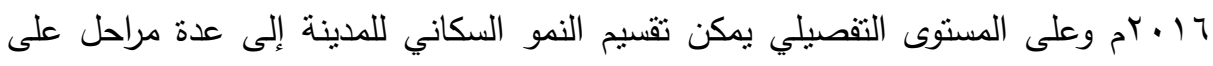
النحو التالي:

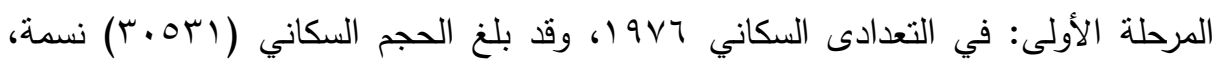
بنسبة فى تقدر بr\% من جملة سكان مركز أشمون.

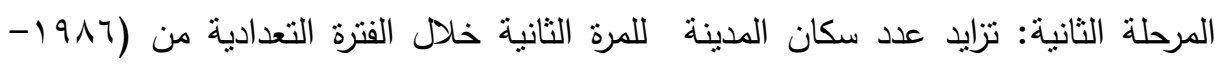

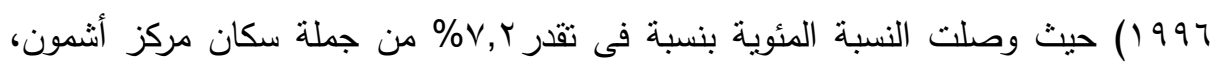

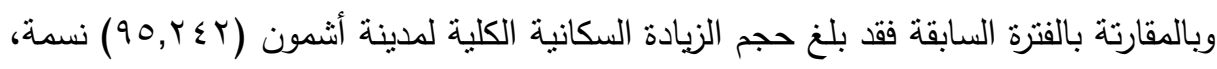
أى ما يعادل ^، \%\% زيادة سكانية كما شهدت هذه الفترة أكبر معدل نمو سكانى خلال 


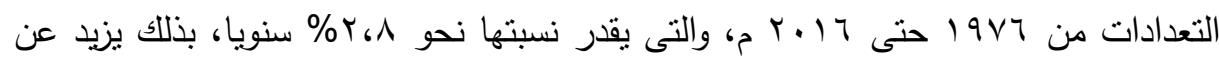

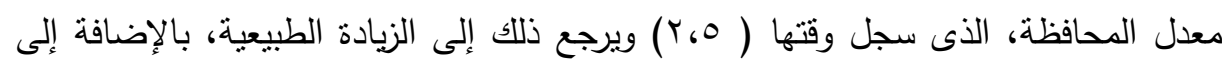

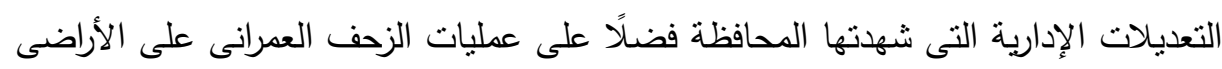
الزراعية فى الفترة الأخيرة.

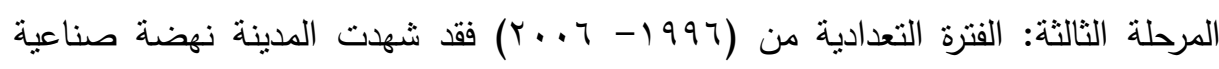
وخدمية كبرى وتوافر فرص العمل بها، واستقبالها لهجرات وافدة من الريف المجاور للإستنيطان

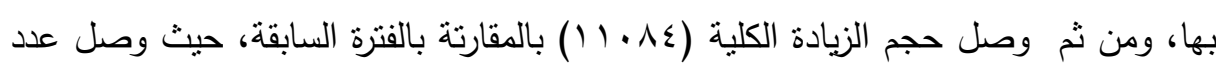

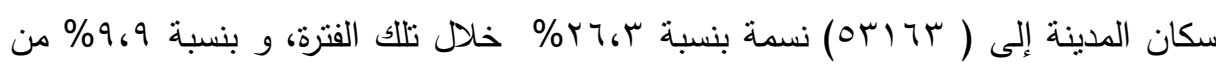
جملة سكان المركز ، كم انخفض معدل النمو السنوى لهذه الفترة عن سابقتها، والذى قدر بنحو لوكابه

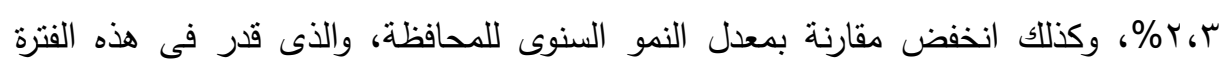
بنحو ع، \%

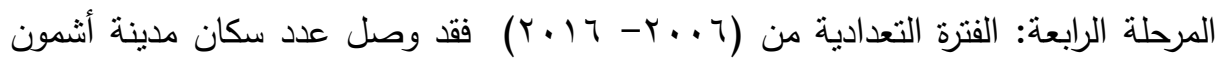

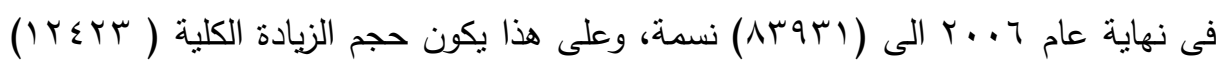

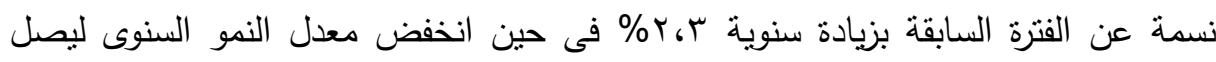

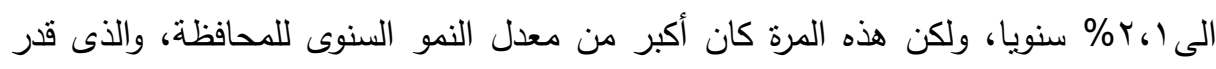

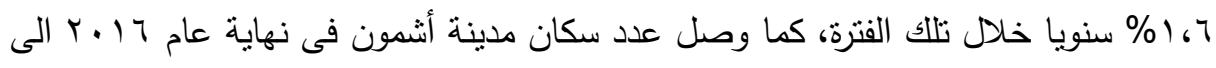

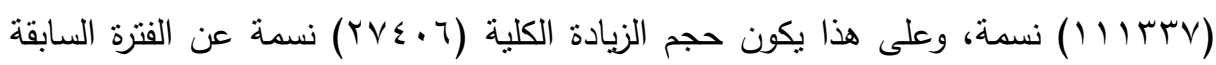

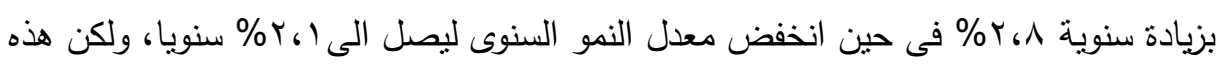

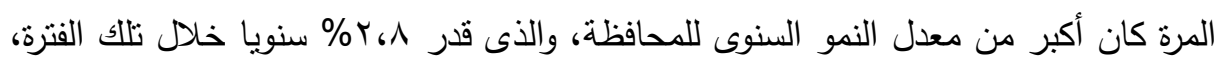
وترجع الزيادة السكانية هنا فى هذه الفترة الى الإنفتاح والتوسعات الكبيرة التى شهدتها المدينة خلال تللك الفترة وإعادة التخطيط الهيكلى لها مما أدى إلى فوز مدينة أنثمون بأجمل مدينة على مستوى الجمهورية من حيث التنمية الثشاملة وتكامل خدماتها. 
جدول (ץ): تغير نمو سكان مدينة بنها مقارنة بمدن محافظة القليوبية فيما بين تعدادي

$$
(r \cdot 17-19 \vee 7)
$$

\begin{tabular}{|c|c|c|c|c|}
\hline معدل النمو السكاني & \multicolumn{2}{|c|}{ الزيادة الكلية } & عدد السكان & الفترة \\
\hline$\%$ & نسبة الزيادة \% & العدد & (نسمةة) & التعدادية \\
\hline$r, \Lambda$ & 7,7 & $19 v \leq 0$ & $\wedge \wedge \wedge \leqslant 0$ & 1987 \\
\hline$r, 1$ & $\vee, \Lambda$ & YY107 & 1108.1 & 1917 \\
\hline$r, V$ & $\Lambda, 0$ & $r .191$ & Iro人9r & 1997 \\
\hline$r, 0$ & $\Lambda, 7$ & Y) 1.9 & $10 \mathrm{VV} .1$ & $r \ldots T$ \\
\hline$r, r$ & 9.4 & $1 Y 900$ & $1 V .707$ & 1.17 \\
\hline
\end{tabular}

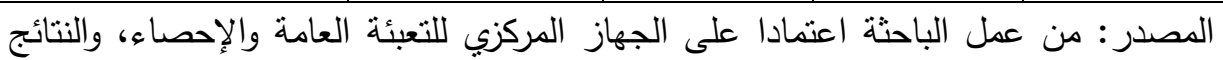

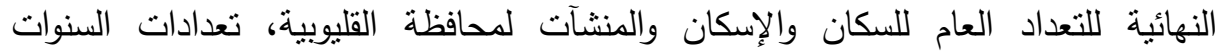

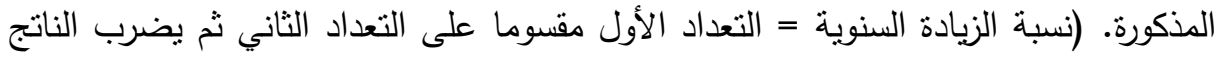

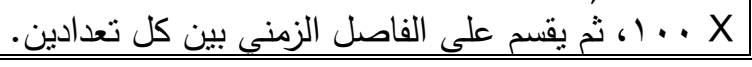

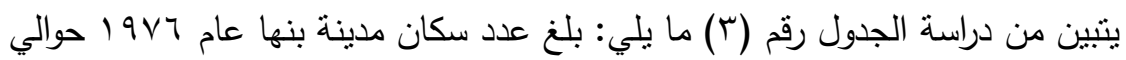

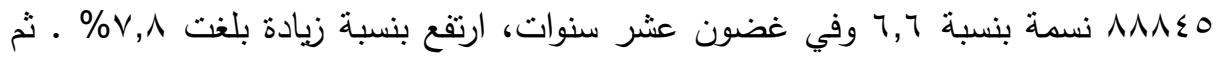

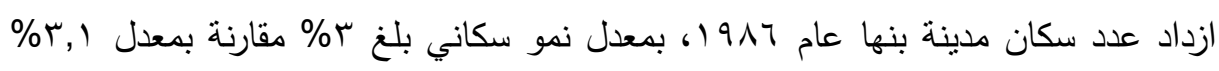
في حضر محافظة القليوبية، وتعتبر هذه الفترات أعلى فترات النمو السكاني لمدينة بنها.

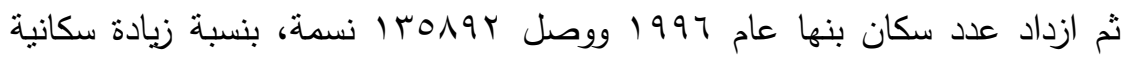

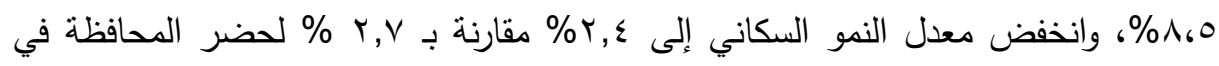
الفترة نفسها، ولعل هذا الانخفاض يعزى لاستقرار المدينة إداريًا، ويضاف إلى ذلك الك أن سكان

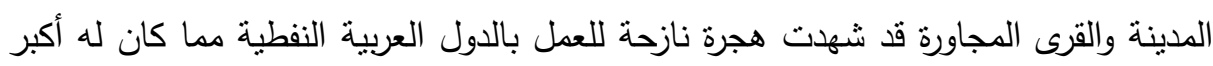

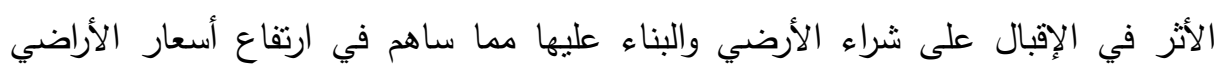
والإيجارات، ولم يتحمل غير القادرين الزيادة في إيجارات السكان والانتقال للقرى المجاورة الإنياه للمدينة بالضفة الغربية.

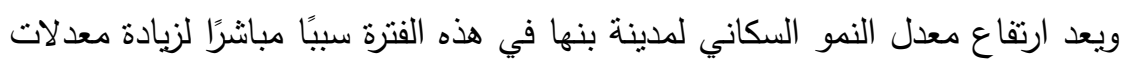
نمو رقعتها العمرانية نحو الأطراف زحفًا على الأراضي الزراعية، ويرجع ذلك لكون لكونها أكثر 
هدوءًا والرغبة في بناء مساكن واسعة لأفراد الأسرة، وكذلك إقبال العمالة المصرية على الهجرة للعمل في الخارج مما أدى لورود رأس مال لثراء أراضي في أطراد الأفرة المدينة. (إسماعيل، (r) : : $19 \wedge \mathrm{V}$

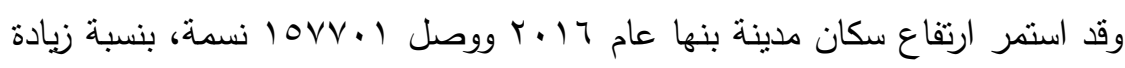

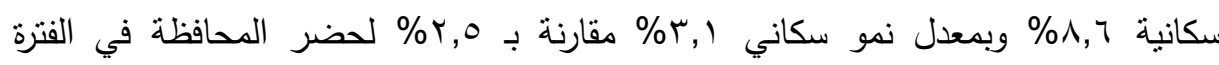

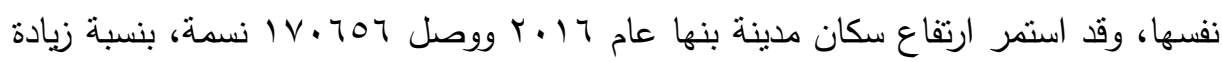

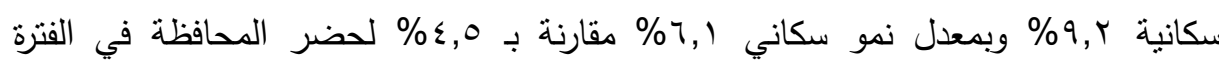
نفسها، وعند مقارنته بحضر محافظة القليوبية اتضح نوازي منحنى النمو السكاني في كليهما وإن تفوق معدل النمو السكاني في حضر المحافظة عنه في مدينة بنها، الأمر يعود إلى

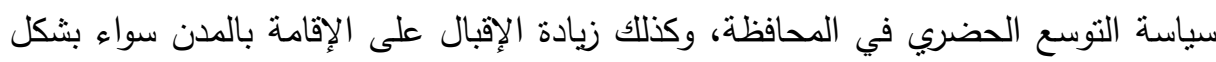
دائم أم مؤقت وهو ما يزيد من معدلات نمو سكان الحضر السنوية.

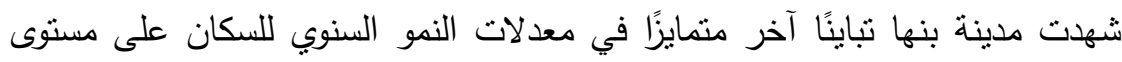

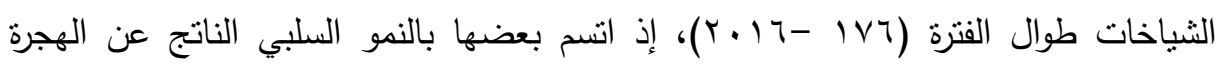
النازحة والممثلة في شياخة المنشية وبنها ويرجع السبب في ذلك إلى أن كلا من الثياختين يمثلان الكتلة القديمة للمدينة والمحددة المساحة وليس هناكه ولئه مجال للاتساع الأفقي ويقتصر على الاتساع الرأسي، في حين اتست الثياخات الأخرى بنذبذب نموها في شياخات الرياح

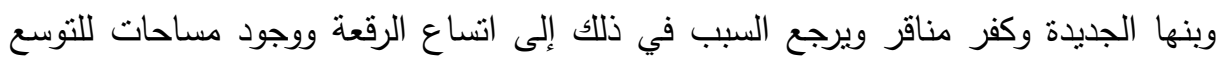
الأفقي عليها.

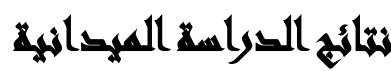

• أظهرت نتائج الدراسة إلى أن هناك أسباب وعوامل أدت إلى النتوه الحضري في الددن

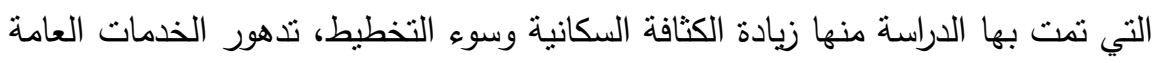
في بعض المناطق خاصة الخدمات الصحية والتعليمية وخدمات المياه وغيرها، تدهور البنية الحضرية وهشاشتها. 
كما بينت الدراسة أن لظهور قانون الحاكم العسكري في نهاية التسعينات رقم ا لسنة

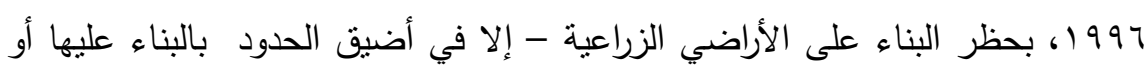

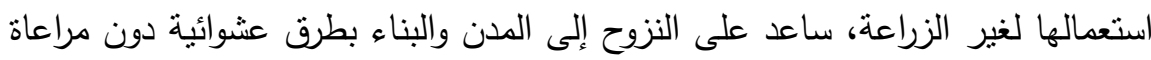

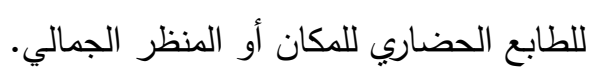
أظهرت الدراسة أن الانفتاح الاقتصادي والذي بدأ في السبعينيات من القرن الماضئي ساهم في رواج السوق العقارية بشكل كبير ، إضافة إلي اتجاه المصريين العاملين بالخارج إلي الاستثمار العقاري بشكل كبير خاصة في الثياخات الحضرية.

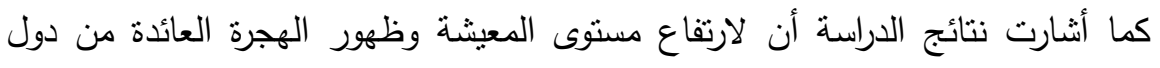

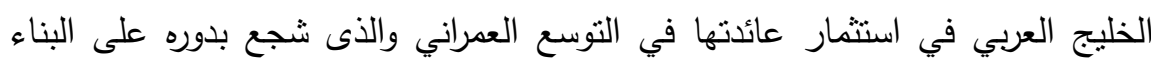

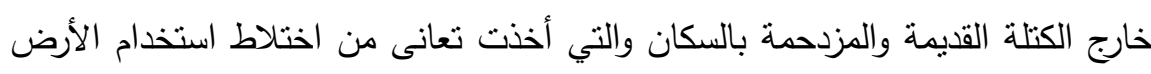

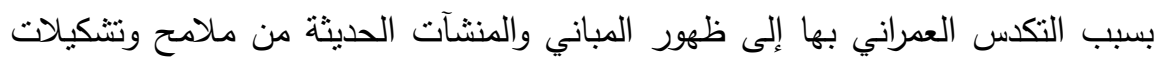

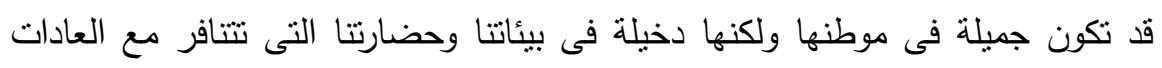
والتقاليد والقيم الاجتماعية لمجتمعنا.

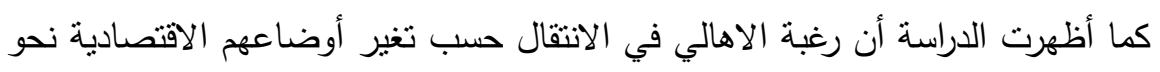

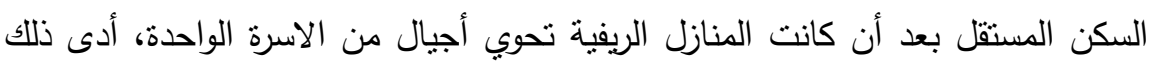

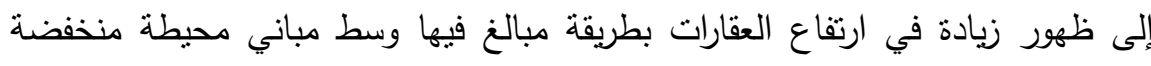
الارتفاع مما أدت إلى انقضاء الخصوصية في النسبة للمباني القريبة منها.

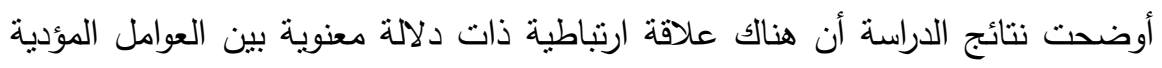

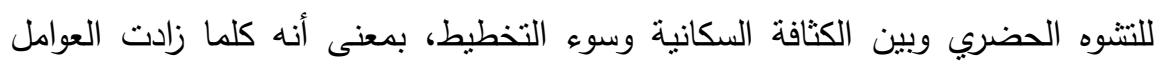

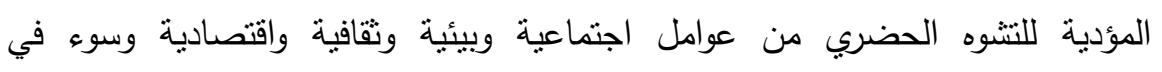
التخطيط، تؤدى بدورها إلى تغيير في الثكل والمظهر العام للمدن. 


\section{تروسيامت التوراسما}

العمل على تفعيل الدور الرقابي من قبل الججالس المحلية والأحياء للقضاء علي ظاهرة

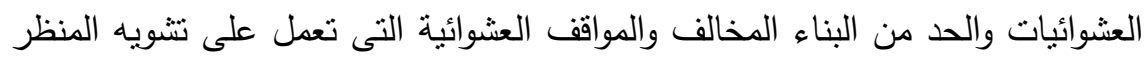

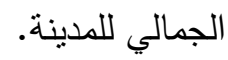

وضع اطر تصميمية محددة لجميع المباني داخل الددينة لوجود لوحات الدعاية والإعلان

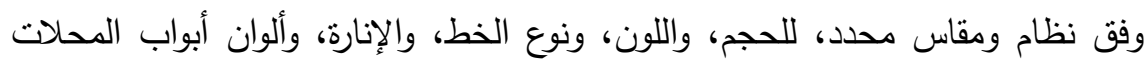
وتوحيد بروز المظلات، الأمر الذي يضفي لكسه جمالية للشوارع بعمل على تتاغم الثنل الجمالي اللمدينة.

العمل على إعادة نوجيه معتقدات الناس وقيمهر وسلوكياتهم عن طريق مواجهة المشكلات التغيرات الاجتماعية، بحيث يمكن للثباب بكل مدينة المساهمة بدئ بدور إيجابي

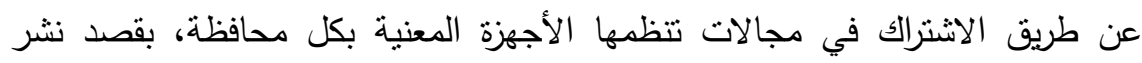
الوعى بأهمية التصدي لظاهرة العشوائيات والمحافظة على الطابع الحضري للمدينة. • على الدولة الاهتمام بخطط التتمية وإعادة النوازن بين الريف والحضر و تفعيل المشاركة الثعبية و إعادة الاهتمام بالبيئة ووضع استراتيجية فعالة للإسكان وتقعيل وسائل الإعلام والاهتمام بالمنظمات النظوعية و المتخصصة. • سن القوانين والتثريعات الخاصة بالبناء على أو بجوار الأماكن الأثرية لحماية

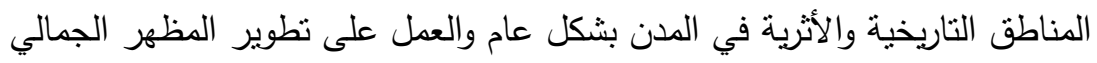

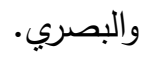

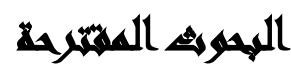

1- اجراء الكثير من الدراسات التي تحث المسئولين على الاهتمام بالمظهر العام للددن والمجالات المرتبطة بها.

r- دراسة اتجاهات الثباب نحو الهجرة إلي الددن الصناعية والعزوف عن العمل بالزراعة

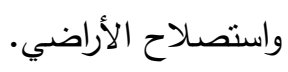




\section{zall}

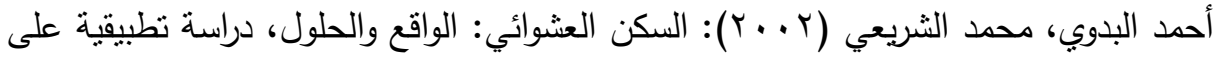
مدينة الزقازيق.

أحمد جميل شامية (ب ( ب): دراسة تحليلية للتلوث البصري في مدينة غزة بفلسطين، رسالة ماجستير غير منشورة، كلية الهندسة، الجامعة الهاتة

$$
\text { الاسلامية - غزة: ماهيز }
$$

أحمد على اسماعيل (9AvV) (1): دراسات فى جغرافية المدن، دار التقافة العربية القاهرة، الطابعة

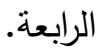

انس أسكيف (99V (1)): التلوث البصري، دراسة في النظام العمراني في مدينة حلب، كلية الهندسة المعمارية، جامعة حلب.

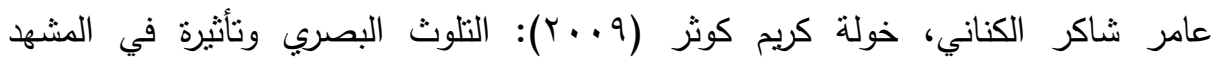

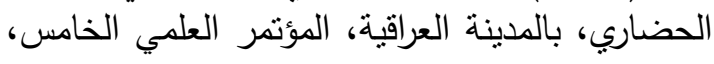

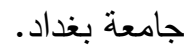

عبد اللطيف محمد خليفة ب99 1 : ارتقاء القيم ، دراسة نفسية ، عالم المعرفة، القاهرة . صلاح الدين عبد الفتاح (1911) : الخصائص الإجتماعية والإقتصادية لسكان المناطق

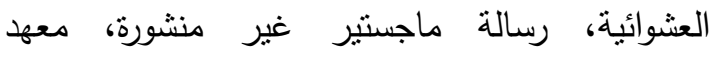

الدراسات والبحوث البيئية، جامعة عين شمس.

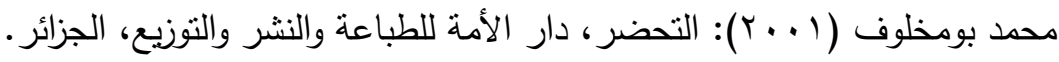

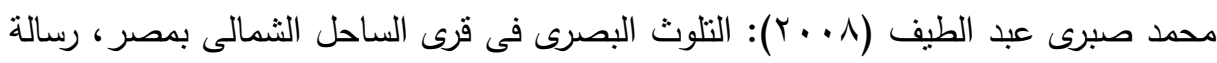

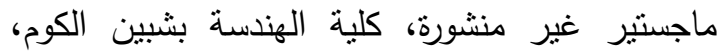

\section{جامعة المنوفية.}

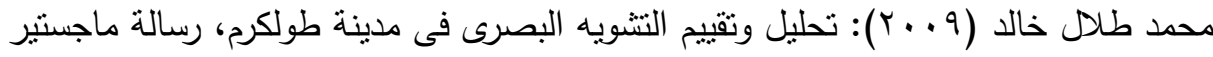

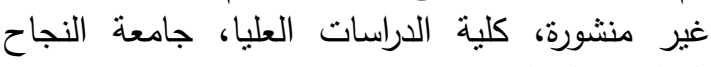

$$
\text { الوطنية، فلسطين. }
$$

$$
\text { المجلد السابع والأربعون، الجزء الثالث، سبتمبر } 9 \text {. }
$$




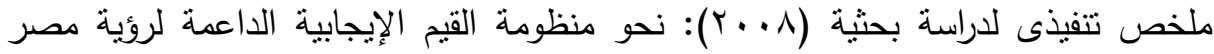

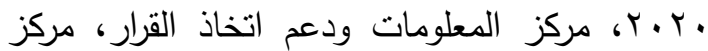

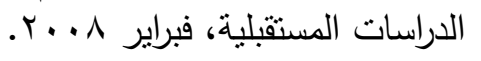

ميمونة مناصرية (0 . . ץ): التحول الديمغرافي وآثاره في التتوه العمراني، رسالة ماجسنتير غير منشورة، كلية العلوم الإنسانية والعلوم الإجتماعية، العناية،

$$
\text { جامعة منتوري قسنطينة، الجزائر. }
$$

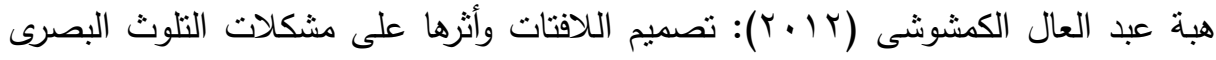

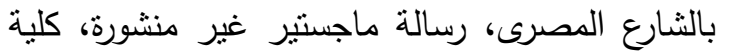
الفنون النطبيقية، جامعة الاسكندرية.

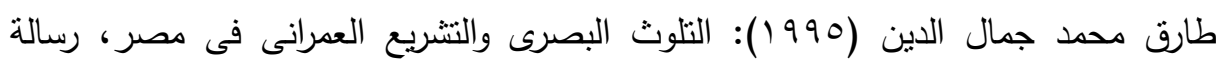
ماجستير غير منشورة، كلية الهندسة، جامعة القاهرة.

علام محمد أحمد (991 (191): العوامل الاجتماعية للأحياء المتخلفة فى مدينة القاهرة، رسالة ماجستير غير منشورة، كلية الهندسة، جامعة القاهرة.

Gaspari, G. M.; Gopeenatha, N. and Muniyappa, P. (2015): Social Development and Preservation Of Historical and Culture Heritage; Bangalore Metro Line UG- 1. In Engineering Geology For Society and TerritortVoulme 8)..

Mohamed, A. B. S. (2014). ALEXANDRIA'S SOCIAL ENVIRONMENT IMPACT ON PUBLIC SPACES. Global Journal of Arts Humanities and Social Science. 
مجلة العلوم البيئية

معهز الدراسات والبحوث البيئة - جامعة عين شمس لئس

\title{
SOCIAL VARIABLES LEADING TO URBAN DISTORTION \\ CASE STUDY ON A GROUP OF EGYPTIAN CITIES
}

\author{
Ebtisam A. Ahmed ${ }^{(1)}$; Saleh S. Abdel Azeem ${ }^{(2)}$ \\ and Ghada A. Abdel Ghani ${ }^{(3)}$
}

[5]

1) Post-graduate student 2) Faculty of Arts, Ain Shams University

3) Faculty of Engineering, Al-Menofia University

\begin{abstract}
The study aimed to identify the phenomenon of Social variables leading to urban distortion. The study was applied on a sample of three cities in the Delta (Shebin El-Koum - Ashmon - Benha). This study belongs to the descriptive type of studies, using the social survey through a random sample of (200) items distributed on three cities using the questionnaire form. The researchers relied on some statistical methods, including ( $\mathrm{T}$ ) test, frequencies, ratios and correlation coefficients.

The study reached to a number of results as follows: there are some causes and factors that led to the urban distortion such as: the increase in population density, deterioration of public services in some areas especially; health, education, water and other services, in addition to, the deterioration of the urban structure and its fragility. The study also displayed that the emergence of the Military Governor's Law at the end of this period No. 1 of 1996, with the prohibition of building on the agricultural land, except in the narrowest extent of building or using it for non-agriculture, led to moving to the cities and building in random ways. The study also showed that the economic openness which started in the 1970s in the real estate market was very high, in addition to the tendency of the Egyptians working abroad to invest in real estate especially in the urban districts. The results of the study also indicated
\end{abstract}

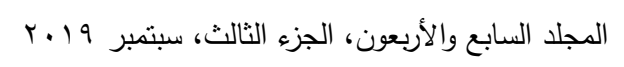


that the high level living and the emergence of migration returning from the Arab Gulf countries to invest their revenue in urban expansion, which in turn encouraged the construction outside the old block which is crowded with the population, which suffer from the mixing of the use of land due to the urban accumulation to the emergence of modern buildings and constructions from features and formations that may be beautiful in their homeland but exotic in our environments and civilizations that are contrary to the customs, traditions and social values of our society. The study also showed that people desire to move according to their changed economic conditions towards the independent housing because the rural houses contain generations of the same family. The elevations are exaggerated in the midst of low-rise surrounding buildings, leading to a lapse of privacy for nearby buildings.

The study recommends the following: working on activation of the control role by the local councils and quarters in order to eliminate the slums phenomenon and restrict the informal building that distorts beauty of the city. Setting determinant designing frames for the city's buildings to restrict or prohibit the advertisement banners and to make them du to specific criteria regarding the color, the size, the font type, lightening, colors of doors of shops and unifying the umbrellas' limits and jutting-outs; this can create aesthetic touch to the city. Working on re-directing of people beliefs, values, and behaviors through encountering the problems of the social and changes, so, youth can act positively in every city through participation in fields organized by the official authorities in each governorate. 